NBER WORKING PAPER SERIES

\title{
DECOMPOSING THE TWIN-PEAKS IN THE WORLD DISTRIBUTION OF OUTPUT-PER-WORKER
}

\author{
Paul Beaudry \\ Fabrice Collard \\ David A. Green \\ Working Paper 9240 \\ http://www.nber.org/papers/w9240
NATIONAL BUREAU OF ECONOMIC RESEARCH 1050 Massachusetts Avenue
Cambridge, MA 02138 \\ October 2002
}

This paper was written while the second author was visiting the Department of Economics, University of British Columbia. We have benefited from discussions with D. Acemoglu, C. Blackorby, A. Kotwal, T. Lemieux, G. Verdier, A. Young and from presentation at the CIAR 2002 summer workshop. The views expressed herein are those of the authors and not necessarily those of the National Bureau of Economic Research.

(C) 2002 by Paul Beaudry, Fabrice Collard, and David A. Green. All rights reserved. Short sections of text, not to exceed two paragraphs, may be quoted without explicit permission provided that full credit, including (C) notice, is given to the source. 
Decomposing the Twin-peaks in the World Distribution of Output-per-worker

Paul Beaudry, Fabrice Collard and David A. Green

NBER Working Paper No. 9240

October 2002

JEL No. O33, O41

\section{$\underline{\text { ABSTRACT }}$}

This papers examines changes in the distribution of per-worker-output across countries over the period 1960-98, with a particular focus on identifying the forces behind the hollowing out of the middle of the distribution and the associated emergence of a twin-peaks phenomenon. The main finding of the paper is that most of the change in shape of the world distribution of income between 1960-1998 can be accounted for by changes in the parameters driving the growth process. In particular, we show that role of physical capital investment and population growth in affecting output growth has increased substantially over the period and that this increase can account for all the hollowing-out of the distribution. In contrast, we do not find that changes in the distribution of variables played much of a role, nor do we find any significant effects coming through non-linear convergence mechanisms or increased importance of education. Our results suggest that research aimed at understanding changes in the world distribution of income should focus on explaining why the social returns to physical capital accumulation where so high over the period 1978-98. The paper ends by discussing elements that help understand this phenomena.

$\begin{array}{lll}\text { Paul Beaudry } & \text { Fabrice Collard } & \text { David A. Green } \\ \text { Department of Economics } & \text { CNRS \{GREMAQ and IDEI } & \text { Dep. of Economics } \\ \text { Univ. of British Columbia } & \text { Universite de Toulouse I } & \text { Univ. of British Columbia } \\ \text { 997-1873 East Mall } & \text { Manufacture des tabacs, batiment F } & \text { 997-1873 East Mall } \\ \text { Vancouver, B.C. } & \text { 21 allee de Brienne } & \text { Vancouver, B.C. } \\ \text { Canada, V6T 1Z1 } & \text { 31000 Toulouse } & \text { Canada, V6T 1Z1 } \\ \text { CIAR and NBER. } & \text { France } & \text { green@econ.ubc.ca } \\ \text { paulbe@interchange.ubc.ca } & \text { fabrice.collard@univ-tlse1.fr } & \end{array}$




\section{Introduction}

Over the period 1960 to 1998, the shape of the distribution of output per worker (and output per capita) across countries has changed considerably. As discussed in Quah [1997] and Jones [1997] among others, in 1960 this distribution was clearly uni-modal and close to log-normal. However, over time, the middle of distribution hollowed-out quite substantially, as mass moved away from the mean of the distribution towards two new modes. This process - which Quah named the twin-peaks phenomenon - is the object of study of this paper. The approach we adopt in the paper is to decompose the observed changes in the world distribution of output per worker ${ }^{1}$ over the period 1960-1998 into three main components: (i) changes in the distribution of driving forces that affect growth across countries, (ii) changes in the importance of these driving forces and (iii) changes in the distribution of residual or unobservable factors affecting growth. ${ }^{2}$ We believe that providing such a decomposition will help orient research interested in the world distribution of income in the same manner that within-country decompositions of wage distributions have helped direct recent research in labour economics.

The first observation we make, which thereafter influences our approach to the data, is that the twin-peaks phenomenon is especially noticeable among non-sub-Saharan African (NSSA hereafter) countries. ${ }^{3}$ This observation is of interest since it immediately eliminates the possibility that the twin-peaks phenomenon is driven exclusively by the poor growth performances of the sub-Saharan African countries. We therefore find it useful to first focus on understanding the changes in the distribution of output per worker across NSSA countries before tackling the whole distribution. The second important observation we make is that the hollowing-out of the middle of the output per worker distribution (at least for NSSA countries) essentially began around 1978. In effect, before 1978 this process was not at all apparent among NSSA countries. This leads us to pose the question: what differences between the period 1960-1978 and 1978-1998 can account for the observed changes in the shape of the world distribution of output per worker?

The main finding of the paper is that most of the change in shape of the distribution of output per worker in NSSA countries between 1960-1978 versus 1978-1998 can be accounted for by changes in the importance of two traditional growth factors, that is, increases in the impact of the rate of investment in physical capital (or the savings rate) and the rate of population growth on output per worker. Indeed, our estimates indicate that the importance of these factors has increased by a magnitude of about 3 within the 1960-1998 period. In contrast, we do not find that changes in the distribution of investment rates, rates of population growth, school enrolment rates or residual factors have played much of a role. Similarly, we do not

\footnotetext{
${ }^{1}$ Throughout the paper we will refer to the world distribution of output as the distribution of output across countries, and not the distribution of income across individuals around the world. The later distribution has recently been studied by Sala-i-Martin [2002].

${ }^{2}$ Our approach builds on the labor literature that studies changes in the distribution of wages (see e.g. Juhn, Murphy and Pierce [1993]).

${ }^{3}$ Our use of the term sub Saharan actually refers to countries neither in northern nor southern regions of Africa.
} 
find any significant effects coming through a non-linear convergence mechanism, scale effects, or increased importance of schooling. As we will show, this result extends to the case where we include all African countries. The only additional factor that appears important when including all African countries in our study is the poor residual draws experienced by sub Saharan African countries in the early period of our study, that is the period 1960-78.

The remainder of the paper is organized as follows. In section 1, we document changes in the distribution of output per worker across NSSA countries between 1960 and 1998. In particular, we document when the twin peaks phenomena emerged. In section 2, we present our method of decomposing change in the distribution of output per worker into changes due to observable and unobservable factors. Section 3 focuses on the stability of the growth process over the period since it is necessary step prior to implementing the decomposition. Section 4 implements this decomposition on our sample of NSSA countries. Our main finding that the changes in importance of two factors - the investment rate and population growth - can account for most of the change in the shape of the distribution. In section 5, we introduce sub-saharan Africa countries into our sample show that a very similar conclusion emerges. Finally, in section 6 we discuss a set of issues that help refine the set of possible explanations that lay behind this process.

\section{The emergence of the twin-peaks phenomenon}

This section describes the changes in the distribution of output per worker in the set of NSSA countries available in the World-Penn Table 6.0 over the period 1960 to 1998 . The list of countries composing our sample is given in appendix A.3. ${ }^{45}$ The measure of output used is real GDP evaluated at constant world prices ${ }^{6}$ and the denominator in our output per worker measure is the number of individuals aged between 15 and $64 .^{7}$

Figure 1 reports the distribution of (log) output per worker across the set of NSSA countries in 1960 and 1998. The plotted distributions are kernel density estimates based on a Gaussian kernel. ${ }^{8}$ Both distributions are expressed as deviations from the given year's mean in order to emphasize changes in the shape of the distribution. It should be noted that the actual

\footnotetext{
${ }^{4}$ We included in our sample all countries that did not have missing data for more that two years between 1960 and 1998. This gave us a sample of 75 countries, with 69 countries having no missing data, and 6 countries with at most two years of missing data. For these 6 countries, the missing data was linearly interpolated. All our results are robust to excluding these 6 countries from the sample.

${ }^{5}$ See appendix A for greater details on the data.

${ }^{6}$ There are several measures of real GDP in the World Penn Tables. Our analysis is robust to the use of these different measures.

${ }^{7}$ It would be preferable to have a more precise measure of the number of workers, but this is not available for a sufficiently wide set of countries. For OECD countries, we have examined the potential biases induced by not taking into account differences across countries in participation rates. We found that using a direct measure of number of workers for OECD countries provides even stronger evidence in favor of the main claim of the paper than that found using population data (see Beaudry and Collard [2002]).

${ }^{8}$ Details can be found in appendix B.
} 
distribution shifted substantially to the right from 1960 to 1998. In fact, the average output per worker increased by $134 \%$ between 1960 and 1998 for this set of 75 countries, implying an average annualized rate of growth of $2.27 \%$. Figure 1 also reports the points in the distribution associated with the interquartile ranges in 1960 and $1998 . .^{9}$ As noted in the introduction, we begin our exploration by focussing on the set on NSSA countries and leave the analysis of the whole sample until section $5 .{ }^{10}$ The advantage of adopting this approach will become clear later.

The distributions in figure 1 display several prominent features. First, the shape of the distribution changed considerably from 1960 to 1998. In particular, the distribution of 1960 (log-)output per worker was uni-modal and, apart from thick tails, was close to normal. As time has passed, mass shifted away from the centre towards two new modes, leading to a bi-modal distribution in the late nineties. This observation corresponds to the so-called twin-peaks phenomenon documented in Quah [1993] and Jones [1997].

Figure 1: Across-Country Income Distribution: 1960-1998

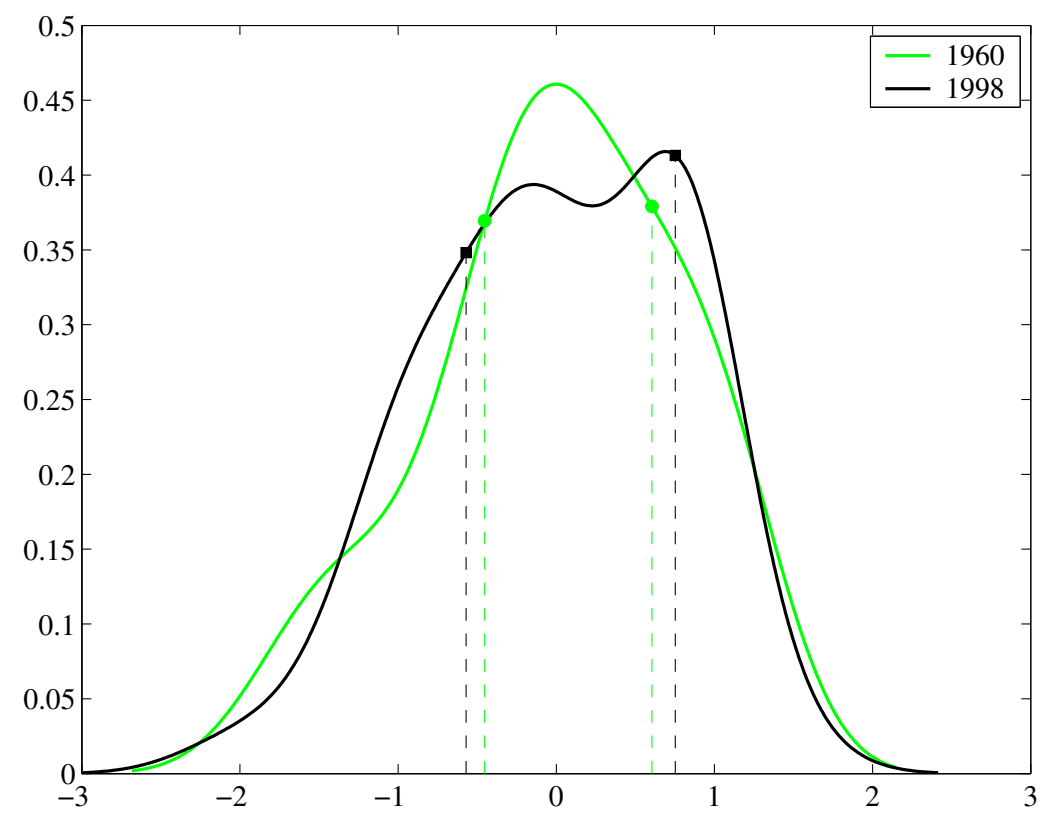

Note: The dashed lines indicate the upper and lower bounds delimiting the interquartile range.

As can also be seen from figure 1, the change in the distribution takes the form of a widening of the interquartile range. Indeed, the interquartile range expanded quite substantially between 1960 and 1998. This movement is also documented in table 1 which reports the interquantile range of the distribution in 1960, 1978 and 1998 and the changes that took place over each sub-period. As can be seen in the table entries, the interquartile range increased by about $26.5 \%$ over the period. This widening is also found at other decile-ranges of the distribution,

\footnotetext{
${ }^{9}$ The points of the interquartile range are calculated from the raw data and not from the kernel estimates of the density function.

${ }^{10}$ The expositional gains achieved by this approach will become clear in Section 4 .
} 
for example at the 20-80, 30-70 and 40-60 percentile differences. However, the 5-95 percentile difference declined over the same period, indicating there was actually inward movement in the tails at the same time as the widening of the interquartile range. ${ }^{11}$

Table 1: Changes in the interquantile ranges

\begin{tabular}{cccccccc}
\hline \hline & \multicolumn{3}{c}{ Ranges } & & \multicolumn{3}{c}{ Changes } \\
\cline { 2 - 3 } \cline { 6 - 8 } & 1960 & 1978 & 1998 & & $1960-1978$ & $1978-1998$ & $1960-1998$ \\
\hline $05-95$ & 2.6340 & 2.5252 & 2.2923 & & -0.1087 & -0.2329 & -0.3416 \\
$10-90$ & 2.2697 & 2.0666 & 1.9051 & & -0.2030 & -0.1615 & -0.3646 \\
$15-85$ & 1.7623 & 1.3964 & 1.8404 & & -0.3659 & 0.4440 & 0.0782 \\
$20-80$ & 1.3857 & 1.2781 & 1.5925 & & -0.1076 & 0.3144 & 0.2068 \\
$25-75$ & 1.0570 & 0.9465 & 1.3223 & & -0.1104 & 0.3758 & 0.2653 \\
$30-70$ & 0.8704 & 0.8513 & 1.0674 & & -0.0190 & 0.2161 & 0.1971 \\
$35-65$ & 0.6043 & 0.5966 & 0.8204 & & -0.0077 & 0.2238 & 0.2161 \\
$40-60$ & 0.3380 & 0.3835 & 0.4861 & & 0.0456 & 0.1026 & 0.1481 \\
\hline \hline
\end{tabular}

Since a widening of an inter-quartile range can arise in many different forms, it is useful look at how the fraction of countries lying within a given window around the mean changed over time. For example, let us take a window of $\pm 50 \%$ (i.e. 0.5 log-points) around the mean and examine the fraction of countries within that band in 1960 versus $1998 .{ }^{12}$ Table 2 reports these numbers. In 1960, $49 \%$ of countries fell into the $\pm 0.5 \mathrm{log}$-points window, while in 1998 only $39 \%$ of countries fell within the same window. The phenomenon is also apparent if we examine a window of $\pm 0.7 \mathrm{log}$-points around the mean, as the mass of countries lying within this band was $61 \%$ in 1960 and only $49 \%$ in 1998 . These numbers - when taken together with the percentile differences - indicate a widening process that has taken place around the interquartile range and corresponds to a hollowing out of the middle of the distribution with mass moving towards two modes, but without a fattening of the tails.

Table 2: Mass around the mean

\begin{tabular}{lccccccc}
\hline \hline & \multicolumn{3}{c}{ Mass round the mean } & & \multicolumn{3}{c}{ Changes } \\
\cline { 2 - 3 } \cline { 7 - 8 }$\Delta$ & 60 & 78 & 98 & & $60-78$ & $78-98$ & $60-98$ \\
\hline 0.50 & 49.333 & 46.667 & 38.667 & & -2.667 & -8.000 & -10.667 \\
0.60 & 54.667 & 58.667 & 44.000 & & 4.000 & -14.667 & -10.667 \\
0.70 & 61.333 & 66.667 & 49.333 & & 5.333 & -17.333 & -12.000 \\
0.80 & 65.333 & 73.333 & 60.000 & & 8.000 & -13.333 & -5.333 \\
0.90 & 70.667 & 78.667 & 73.333 & & 8.000 & -5.333 & 2.667 \\
1.00 & 78.667 & 81.333 & 78.667 & & 2.667 & -2.667 & 0.000 \\
\hline \hline
\end{tabular}

\footnotetext{
${ }^{11}$ Accordingly, the variance of the distribution only increased marginally over the period.

${ }^{12}$ This amounts to compute the mass of countries lying within the band $\left[\bar{y}_{t}-\Delta ; \bar{y}_{t}+\Delta\right]$ where $\Delta$ determines the width of the window.
} 
The second issue we want to examine is the timing of this hollowing-out process. Panels (a) and

Figure 2: Distributional Dynamics

(a) Percentiles differences

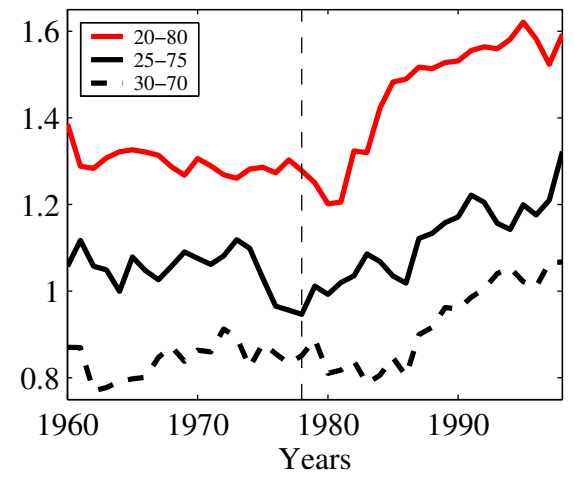

(b) Mass around the mean

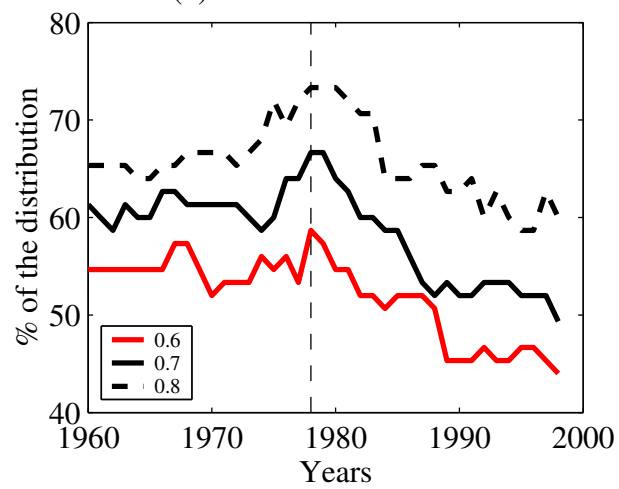

(b) of figure 2 plot, respectively, key movements in percentile differences and our mass around the mean statistics for the entire period 1960 to 1998. From panel (a), one can see that the 20-80 percentile difference, the interquartile range and the 30-70 percentile differences were all rather stable through the sixties and much of the seventies but that somewhere around 1978 all three began to rise sharply. The interquartile range, for example, actually declined by about 11\% from 1960 to 1978 but increased by almost 40\% between 1978 and 1998. For easy reference, table 1 reports the actual levels of these on other percentile ranges for the years 1960, 1978 and 1998. Thus, figure 2 suggests that the particular widening of the distribution observed in figure 1 has arisen only since 1978.

The notion that there was an important change starting around 1978 is reinforced in panel (b) where we plot the time series for the fraction of countries lying within a given window around the mean. We report information corresponding to windows of $\pm 0.6,0.7$, and 0.8 log-point around the mean. The actual values for these windows for the years 1960, 1978 and 1998 are given in table 2. Just like the percentile differences in panel (a), the mass around the mean was rather stable up until the late seventies (1978), then it fell sharply over the eighties and the nineties. Overall, these figures indicate that the twin-peaks phenomenon observed in figure 1 has arisen mainly since 1978. This pattern is confirmed in 3, where we plot the 1978 output per worker distribution along with the 1960 distribution. The figure shows the interquartile range had actually reduced over this period and there was not yet any hollowing out of the middle of the distribution. ${ }^{13}$

\footnotetext{
${ }^{13}$ It should be noted that a twin-peaks phenomenon is even more pronounced when we look at output per capita rather that output per worker. However, the distribution of output per capita differs from that of output per worker in that it shows widening not only in the middle of the distribution but also in the tails. Consumptionper-capita presents a similar pattern, but with less bi-modality. (graphs are available from the authors upon request)
} 
Figure 3: output per worker Distribution:1960-1978

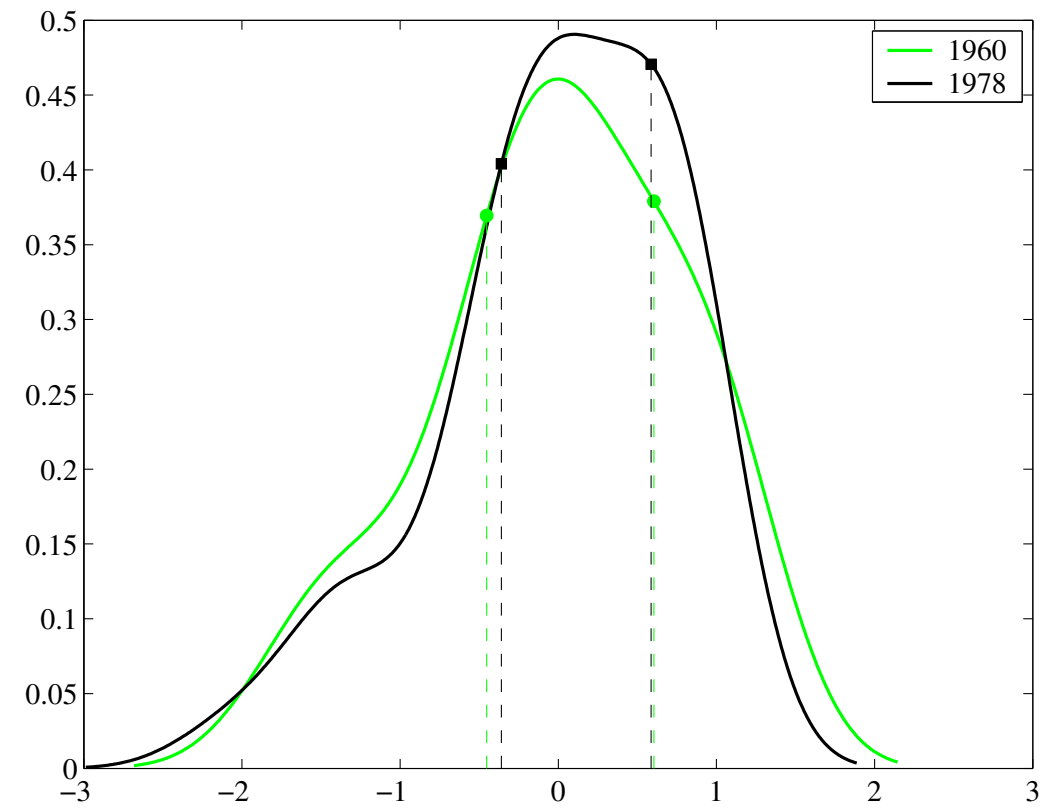

\section{A framework for decomposing changes in the cross-country distribution of output per worker}

The object of this section is to present a simple framework for assessing the importance of different factors in explaining the observed changes in the world distribution of output per worker. Our strategy, which is quite standard ${ }^{14}$, is to provide a decomposition of the changes in the distribution that emphasizes three main factors: (i) changes in the distributions of observable factors affecting growth, (ii) changes in the importance of these observable factors, and (iii) changes due to residual or unobserved factors. To this end, let us start with the identity given in equation (1), whereby a country's log-level of output per worker in 1998, denoted $y_{i}^{98}$ is expressed as the log-level of output in $1960\left(y_{i}^{60}\right)$ plus the sum of its growth rate between 1960-1978 $\left(G_{i}^{60-78}\right)$ and its growth rate between $\left(G_{i}^{78-98}\right)$. We explicitly choose to decompose the growth rate over the entire period into growth between 1960-1978 and 1978-1998 based on our discussion in the previous section suggesting 1978 as the date after which the twin peak phenomena started to emerge.

$$
y_{i}^{98}=y_{i}^{60}+G_{i}^{60-78}+G_{i}^{78-98}=y_{i}^{60}+18 \times g_{i}^{60-78}+20 \times g_{i}^{78-98}
$$

In equation (1), $g_{i}^{j}$ is the annual rate of growth of output in country $i$ over the sample period $j=\{60-78,78-98\}$. The growth rates for each of the sub-periods can then be expressed, as in the standard growth regression literature, as the sum of a force of convergence related to initial levels

\footnotetext{
${ }^{14}$ Our approach is closely related to that used in the labour literature for decomposing changes in the distribution of individual outcomes such as wages. For an example see Juhn et al. [1993]. However, because of the dynamic aspect of our problem, certain new issues arise.
} 
of income-per-worker plus the effects of a set of country specific variables $X_{i}$ which potentially explain growth.

$$
\begin{aligned}
& g_{i}^{60-78}=\beta_{0}^{60-78}+\beta_{y}^{60-78} y_{i}^{60}+X_{i}^{60-78} \beta_{x}^{60-78}+\varepsilon_{i}^{60-78} \\
& g_{i}^{78-98}=\beta_{0}^{78-98}+\beta_{y}^{78-98} y_{i}^{78}+X_{i}^{78-98} \beta_{x}^{78-98}+\varepsilon_{i}^{78-98}
\end{aligned}
$$

In the above two equations, $\varepsilon_{i}^{j}$ denotes the component of growth that is accounted for by unobservable forces, with the distribution of these residuals being allowed to change over time.

In such a framework, changes in the distribution of $y^{98}$ relative to $y^{60}$ come through the two growth rate equations. Given the reference date of 1978, an interesting question to pose is what changed in the period 1978-1998 versus 1960-1978 to bring about a distribution which is bi-modal and which has a wider inter-quartile range? This change between period can be allocated to four sources: (i) changes in the distribution of the driving variables (i.e. changes in the distribution of the X's and $y_{0}$ between 1960-78 versus 1978-98), (ii) changes in the magnitudes of the $\beta$ 's, (iii) changes in the distribution of unobservable forces and (iv) a residual category which corresponds to that continuation of the (minor) dynamic process observed over the 1960-1978 period. In light of this decomposition, we can easily build counterfactual income distributions for 1998 which control for one or more of these different effects.

As an example of this approach, consider evaluating the effects due to changes in the distribution of the $X$ 's. To do this, we can construct a counterfactual growth rate for the second period, say $g_{i}^{X}$, which uses the distribution of $X$ 's observed over the first period (1960-78) to replace the actual $X$ 's observed in the second period. This counterfactual growth rate is then given by

$$
g_{i}^{X}=\beta_{0}^{78-98}+\beta_{y}^{78-98} y_{i}^{78}+\mathbf{X}_{\mathbf{i}}^{\mathbf{6 0}-78} \beta_{x}^{78-98}+\varepsilon_{i}^{78-98}
$$

Using the definition of the rate of growth, we can build a counterfactual distribution of $y_{i}^{98}$, denoted $y_{i}^{X}$ as follows

$$
\begin{aligned}
y_{i}^{X} & =y_{i}^{78}+20 \times g_{i}^{X} \\
& =y_{i}^{78}+20 \times\left(\beta_{0}^{78-98}+\beta_{y}^{78-98} y_{i}^{78}+\mathbf{X}_{\mathbf{i}}^{\mathbf{6 0}-\mathbf{7 8}} \beta_{x}^{78-98}+\varepsilon_{i}^{78-98}\right) \\
& =y_{i}^{78}+20 \times\left(\beta_{0}^{78-98}+\beta_{y}^{78-98} y_{i}^{78}+X_{i}^{78-98} \beta_{x}^{78-98}+\varepsilon_{i}^{78-98}\right)+20 \times\left(\mathbf{X}_{\mathbf{i}}^{\mathbf{6 0}-\mathbf{7 8}}-X_{i}^{78-98}\right) \beta_{x}^{78-98} \\
& =y_{i}^{98}+20 \times\left(\mathbf{X}_{\mathbf{i}}^{\mathbf{6 0}-\mathbf{7 8}}-X_{i}^{78-98}\right) \beta_{x}^{78-98}
\end{aligned}
$$

Likewise, the effects of changes in the magnitude of the $\beta_{x}$ on the distribution of income can be measured by constructing the rate of growth, $g_{i}^{\beta_{x}}$, that controls for changes in $\beta_{x}$

$$
g_{i}^{\beta_{x}}=\beta_{0}^{78-98}+\beta_{y}^{78-98} y_{i}^{78}+X_{i}^{78-98} \boldsymbol{\beta}_{\mathbf{x}}^{\mathbf{6 0}-78}+\varepsilon_{i}^{78-98}
$$

similar calculations as in system (5) yields

$$
y_{i}^{\beta_{x}}=y_{i}^{98}+20 \times X_{i}^{78-98}\left(\boldsymbol{\beta}_{\mathbf{x}}^{\mathbf{6 0}-\mathbf{7 8}}-\beta_{x}^{78-98}\right)
$$


In the same fashion, changes in either the distribution of the $y_{0}$ 's, the speed of convergence or in the distribution of unobservables can be accounted for by computing the appropriate rates of growth $\left(g_{i}^{y_{0}}, g_{i}^{\beta_{y}}\right.$ and $g_{i}^{\varepsilon}$ respectively) and the implied counterfactual income distributions $\left(y_{i}^{y_{0}}\right.$, $y_{i}^{\beta_{y}}$ and $\left.y_{i}^{\varepsilon}\right)$ as follows: ${ }^{1516}$

$$
\begin{aligned}
g_{i}^{y_{0}} & =\beta_{0}^{78-98}+\beta_{1}^{78-98} \mathbf{y}_{\mathbf{i}}^{\mathbf{6 0}}+X_{i}^{78-98} \beta_{x}^{78-98}+\varepsilon_{i}^{78-98} \\
g_{i}^{\beta_{y}} & =\beta_{0}^{78-98}+\boldsymbol{\beta}_{\mathbf{y}}^{\mathbf{6 0}-\mathbf{7 8}} y_{i}^{78}+X_{i}^{78-98} \beta_{x}^{78-98}+\varepsilon_{i}^{78-98} \\
g_{i}^{\varepsilon} & =\beta_{0}^{78-98}+\beta_{y}^{78-98} y_{i}^{78}+X_{i}^{78-98} \beta_{x}^{78-98}+\boldsymbol{\varepsilon}_{\mathbf{i}}^{\mathbf{6 0}-\mathbf{7 8}} \\
y_{i}^{y_{0}} & =y_{i}^{98}+20 \times\left(\mathbf{y}_{\mathbf{i}}^{\mathbf{6 0}}-y_{i}^{78}\right) \beta_{y}^{78-98} \\
y_{i}^{\beta_{y}} & =y_{i}^{98}+20 \times\left(\boldsymbol{\beta}_{\mathbf{y}}^{\mathbf{6 0}-\mathbf{7 8}}-\beta_{y}^{78-98}\right) y_{i}^{78} \\
y_{i}^{\varepsilon} & =y_{i}^{98}+20 \times\left(\varepsilon_{\mathbf{i}}^{\mathbf{6 0}-\mathbf{7 8}}-\varepsilon_{i}^{78-98}\right)
\end{aligned}
$$

Each of the counterfactual $y$ distributions constructed according to these equations can be used to give an account for what the distribution of income would have been (in a partial equilibrium sense) if one of the components had remained constant over the two periods. It should be noted that - because of the dynamic aspect of our problem - even if we simultaneously take into account the effects of changes in the distribution of $X \mathrm{~s}$, changes in the $\beta \mathrm{s}$ and changes in the distribution of the $\varepsilon$, the resulting counterfactual will not mechanically reproduce the distribution of either 1960 or 1978. Instead, the distribution that arises when we consider all three of these effects simultaneously, which we will denote as the distribution of $y^{R}$, corresponds to an outcome resulting from projecting to 1998 the dynamic process observed between 1960 and 1978, that is, $y_{i}^{R}=y_{i}^{78}+20 \times g_{i}^{60-78}$. Hence, when we evaluate our counterfactuals, it is interesting to compare them with the 1960 and 1978 distribution as well as the distribution of $y^{R} \cdot 17$

Obviously, in order to implement the above decomposition, it is necessary to choose an appropriate set of $X \mathrm{~s}$. Our approach to this issue will be to focus on the forces emphasized in neoclassical growth theory (see Solow [1956]) as well as other possibilities such as effects of education, scale effects and non-linear dependence to initial conditions.

\footnotetext{
${ }^{15}$ Note that if we want to account for both changes in the distribution and the coefficients at the same time, we do not simply have to add up terms, as there exists an interaction between changes in the coefficients and changes in the distribution. For instance, a measure of the effect of an overall change in the driving forces of the growth process (other than convergence) is obtained by building the variable

$$
y_{i}^{X \beta}=y_{i}^{98}+20 \times\left(\mathbf{X}_{\mathbf{i}}^{\mathbf{6 0}-\mathbf{7 8}} \boldsymbol{\beta}_{\mathbf{x}}^{\mathbf{6 0}-\mathbf{7 8}}-X_{i}^{78-98} \beta^{78-98}\right)
$$

${ }^{16}$ Our approach to decomposing a distribution implicitly assumes that the data satisfy the requirement of a pure location model, that is, a mean shift in an $X$ variable is assumed to shift the distribution but not change its shape. Alternatively, we could adopt a less restrictive framework as made possible by quantile regression techniques. However, a preliminary exploration along this front did not reveal any additional insights and therefore we did not pursue this line.

${ }^{17}$ If we wanted to follow the labor literature more closely, it would be reasonable to build all our counterfactuals starting from the distribution of $y^{R}$. However, we have chosen not to do so since it render our analysis less transparent. Nonetheless, we have explored this alternative base for building counterfactuals and it produces identical insights.
} 


\section{Understanding the growth of output per worker}

In order to implement the above decomposition, the first step is to examine the stability of the growth process over the period 1960-78 versus 1978-98. In particular, if the process is stable, then changes in the $\beta$ s cannot account for any of the change in the distribution. To this end, in this section we report a set of cross-country regressions relating growth in output per worker to the initial level of output per worker and other $X$ variables for both the period 1960-78 and 1978-1998. As discussed above, we begin by focusing on the case with only two $X$ variables ( (i) the investment rate and (ii) the rate of population growth) since this will allow us to highlight what we believe to be the major change in the growth process over this period. ${ }^{18}$ Afterwards, we will show how the change in importance of these two factors is robust to the inclusion of other variables, and especially to controlling for human capital accumulation in different forms.

\subsection{The rise in importance of accumulation forces}

Table 3 reports a series of estimates for the regression of the average yearly growth in output per worker on the initial log-level of output per worker, the average yearly growth in labor force and the $\log$ of the average rate of investment. Estimates are reported for both the periods 1960-78 and 1978-98, and are estimated using ordinary least squares (OLS) and weighted least squares (WLS). Averages for both the regressors and regressants are taken over the respective subsamples. In the case of WLS, two weighting schemes were used; the first one (WLS1) weights each country according to the logarithm of its average population over the whole period, and the second one (WLS2) uses the logarithm of average GDP. (Averages for both the regressors and regressants are taken over the respective sub-periods).

Let us first focus on the OLS results. The convergence parameter - the coefficient associated to $y_{0}$ - is close to that reported by other studies (see e.g. Mankiw, Romer and Weil [1992]). Moreover, the estimates of this effect have remained quite stable over the two sub-periods. Indeed, the stability test of this parameter, which we denote by $\mathcal{Q}\left(y_{0}\right)$ in the table, does not indicate a rejection of stability at conventional levels $(\mathrm{p}$-value $=0.855) .{ }^{19}$ In contrast, the estimates reported in the two first columns of table 3 indicate that the magnitude of the coefficients related to the rate of growth of the labor force and the investment/output ratio have increased quite substantially between the two sub-periods. In particular, in the first sub-period (1960-1978), the coefficient measuring the impact of population growth on the growth process was not significant at the conventional 5\% level and amounted to -0.137 , implying that a negative $1 \%$ differential in population growth would have translated into a positive differential in output per worker of about $2.5 \%$ over the 18 year period. In the second sub-period, this coefficient rose to -0.606 , implying the same negative $1 \%$ differential in the rate of growth would have translated in a pos-

\footnotetext{
${ }^{18}$ The data used are those described in section 1 and in appendix A.

${ }^{19}$ Note that all our stability tests are performed allowing for residuals to be correlated within countries over the two samples and the variances in the two samples are allowed to differ.
} 
Table 3: Growth Regressions

\begin{tabular}{lcccccc}
\hline \hline & \multicolumn{2}{c}{ OLS } & \multicolumn{2}{c}{ WLS1 } & \multicolumn{2}{c}{ WLS2 } \\
\cline { 2 - 7 } & $60-78$ & $78-98$ & $60-78$ & $78-98$ & $60-78$ & $78-98$ \\
\hline Const. & 0.185 & 0.208 & 0.161 & 0.213 & 0.180 & 0.211 \\
& $(0.025)$ & $(0.026)$ & $(0.023)$ & $(0.021)$ & $(0.024)$ & $(0.025)$ \\
$y_{0}$ & -0.013 & -0.014 & -0.010 & -0.015 & -0.013 & -0.014 \\
& $(0.002)$ & $(0.002)$ & $(0.002)$ & $(0.002)$ & $(0.002)$ & $(0.002)$ \\
$n$ & -0.137 & -0.606 & -0.118 & -0.623 & -0.133 & -0.618 \\
& $(0.164)$ & $(0.163)$ & $(0.173)$ & $(0.161)$ & $(0.162)$ & $(0.161)$ \\
$i / y$ & 0.016 & 0.027 & 0.018 & 0.025 & 0.017 & 0.026 \\
& $(0.003)$ & $(0.004)$ & $(0.003)$ & $(0.004)$ & $(0.003)$ & $(0.004)$ \\
$R^{2}$ & 0.36 & 0.52 & 0.43 & 0.62 & 0.40 & 0.56 \\
\hline $\mathcal{Q}($ Total $)$ & 14.642 & {$[0.002]$} & 8.590 & {$[0.035]$} & 10.994 & {$[0.012]$} \\
$\mathcal{Q}\left(y_{0}\right)$ & 0.033 & {$[0.855]$} & 2.692 & {$[0.101]$} & 0.424 & {$[0.515]$} \\
$\mathcal{Q}(n, i / y)$ & 12.021 & {$[0.002]$} & 8.212 & {$[0.016]$} & 10.263 & {$[0.006]$} \\
\hline \hline
\end{tabular}

Note: Standard errors in parenthesis, p-values in brackets. WLS1: Weights correspond to the log of the country's population. WLS2: Weights correspond to the log of the country's total real GDP. 75 observations.

itive differential in output per worker of about $12 \%$ over the second sub-period. A somewhat similar pattern is found in the behavior of the coefficient affecting the investment/output ratio. Over the first sub-period, the coefficient affecting investment is 0.016 and significant. Over the second sub-period, this coefficient rose to 0.027. The test statistic, $\mathcal{Q}(n, i / y)$, which tests the null hypothesis of stability in these two parameters across sub-periods, decisively rejects stability $(\mathrm{p}-\mathrm{value}=0.002)$. The restriction of the overall stability of all three coefficients (not including the constant), which is given by $\mathcal{Q}$ (Total), is also clearly rejected, which thereby opens the door to the possibility that changes in coefficients affecting the growth process is a potential candidate for understanding changes in the distribution documented in Section 2.

At this point, it is relevant to ask whether OLS estimates may be dominated by the experiences of a subset of small countries. In order to address this issue, we report in table 3 results from estimation using weighted least squares (WLS) where countries are respectively weighted according to either their total population $(\log )$ or their total GDP $(\log )$. The first striking feature that emerges from the table is that the OLS results remain largely unchanged by moving toward WLS estimation, both in terms of magnitude and stability of the coefficients. For example, the size of the effects of population growth on output growth process is very close to that obtained using OLS. The coefficient is not significant over the first sub-period and becomes significantly negative and large over the second sub-period. Likewise the effects of the investment rate almost doubled between the two sub-periods and the estimates are very close to those obtained by OLS. Furthermore, the stability test for these two variables also leads to strong rejection. The only noticeable exception is found in the stability test of convergence in WLS1, which now indicates that the convergence process may have increased over the two sub-periods. This is not too 
surprising given that this procedure weights the Chinese and Indian experience more heavily, both of which caught up rapidly over this period.

Table 4: Growth Regressions (Instrumental Variables)

\begin{tabular}{lcccccc}
\hline \hline & \multicolumn{2}{c}{ IV1 } & \multicolumn{2}{c}{ IV2 } & \multicolumn{2}{c}{ IV3 } \\
\cline { 2 - 7 } & $60-78$ & $78-98$ & $60-78$ & $78-98$ & $60-78$ & $78-98$ \\
\hline Const. & 0.147 & 0.203 & 0.155 & 0.202 & 0.149 & 0.204 \\
& $(0.027)$ & $(0.029)$ & $(0.035)$ & $(0.032)$ & $(0.027)$ & $(0.028)$ \\
$y_{0}$ & -0.010 & -0.014 & -0.011 & -0.013 & -0.011 & -0.014 \\
& $(0.002)$ & $(0.002)$ & $(0.003)$ & $(0.003)$ & $(0.002)$ & $(0.002)$ \\
$n$ & -0.181 & -0.614 & -0.172 & -0.616 & -0.203 & -0.638 \\
& $(0.171)$ & $(0.164)$ & $(0.170)$ & $(0.166)$ & $(0.172)$ & $(0.166)$ \\
$i / y$ & 0.009 & 0.026 & 0.010 & 0.025 & 0.009 & 0.026 \\
& $(0.004)$ & $(0.005)$ & $(0.006)$ & $(0.006)$ & $(0.004)$ & $(0.004)$ \\
\hline $\mathcal{Q}$ (Total) & 16.444 & {$[0.001]$} & 11.813 & {$[0.008]$} & 16.988 & {$[0.001]$} \\
$\mathcal{Q}\left(y_{0}\right)$ & 0.923 & {$[0.337]$} & 0.439 & {$[0.508]$} & 0.911 & {$[0.340]$} \\
$\mathcal{Q}(n, i / y)$ & 14.936 & {$[0.001]$} & 9.841 & {$[0.007]$} & 15.406 & {$[0.000]$} \\
\hline \hline
\end{tabular}

Note: Standard errors in parenthesis, p-values in brackets. IV1: the variable used for instrumenting $i / y$ is its initial level in each sample period, IV2: the variable used for instrumenting $i / y$ is the average of (c/y) over each the subperiod, IV3: the variables used to instrument $i / y$ and $n$ are the initial level of $(\mathrm{i} / \mathrm{y})$, the average $(\mathrm{c} / \mathrm{y})$ over the sub-sample, and the average growth rate of population over the 15 first periods of the sub-sample. 75 observations.

A second potential concern is the possibility of endogeneity of regressors. To address this issue, we report in table 4 estimation results using different instrumental variable strategies. Three sets of instruments are considered. The first two, IV1 and IV2, address the potential endogeneity of the investment rate with respect to good growth outcomes in each sub-period. In the first case, IV1, we use as an instrument for the average investment rate its initial (log) level in each subperiod. In the second case, IV2, we instrument the investment rate using the country's average saving rate over each period, given by the average level of the consumption to output ratio (in log form) over the sub-period. In the last case, IV3, we use both previously mentioned instruments to instrument the investment rate, moreover we also instrument the rate of population growth using the average growth rate of population 15-64 over only the 15 first years of each sub-period. This latter instrument is aimed at correcting for the potential endogeneity of fertility over each sub-period. As it takes at least 15 years for fertility to affect the labor force, this instrumental variable strategy eliminates any possibility of within period endogeneity of fertility. Hereafter, this particular set of instruments will be referred to as $\mathrm{IV}^{\star}$. As can be seen from the table, the pattern of results are barely affected by the IV procedures. Convergence still displays stability and the coefficients are extremely close to those obtained using OLS. Furthermore, the stability tests indicate that the impact of investment rates and population growth changed significantly between the two sub-periods, as the p-value associated with $\mathcal{Q}(n, i / y)$ is essentially 0 for all 
three IV procedures. The only substantial change associated with these IV procedures is a reduction in the coefficient on the investment-output ratio in the 1960-78 period (from 0.016 with OLS to 0.009 with IV). This implies a larger increase in the impact of the investment rate across periods using IV.

Up to now, we have split our sample in 1978 based on our investigation of the dynamics of the distribution of output per worker, and in particular this choice was motivated by the observation that the widening of the interquartile range seemed to have occurred in the late seventies. Nevertheless, one may question whether or results are robust to changes in the splitting date. To address this issue, we estimated the two growth processes using alternative split dates. In particular, we explored all split dates between 1975 and 1983 and in all cases found significant evidence of a change in the latter sample relative to the earlier sample. In order to get a sense of change in the growth process taking place over time, we report in figure 4 the estimated coefficients on population growth and investment rate as well as the speed of convergence obtained from rolling regressions, with each variable measured in relation to the given window. We chose a size of window of 19 years since it corresponds to half of our sample length. ${ }^{20}$ Each rolling

Figure 4: Rolling regressions
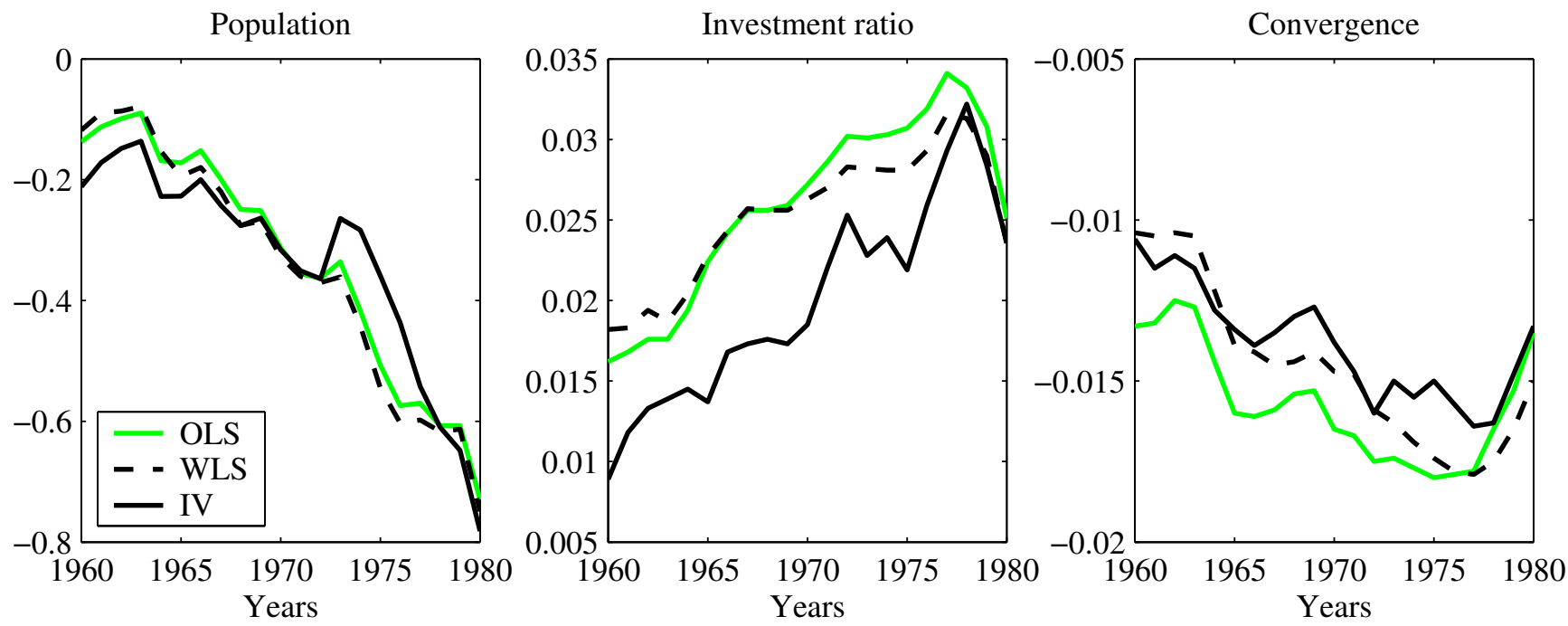

regression was carried out using OLS, WLS and IV. When using WLS, the weight was given by the $(\log )$ level of population. In the IV procedure, we used the set of instruments $I^{\star}$. As can be seen from the figure, the main pattern highlighted in our simple regressions can also be observed in rolling regressions. In effect, there has been a continuous increase in the magnitude of the population growth effect as well as in the investment effect, even though the latter effect decreases slightly at the end of the period. ${ }^{21}$ Furthermore, the size of the coefficients over the

\footnotetext{
${ }^{20}$ In rolling regressions, we estimate a series of regressions with the first regression using observations 1 through 19 , the second regression using observations 2 through 20, etc... We also explored window sizes between 15 to 25 years, all of which led to similar conclusions. In Beaudry and Collard (2002) this approach was used to examine changes in the growth process among OECD country's.

${ }^{21}$ In effect, this later decline suggests that the period of especially high gains to physical capital accumulation
} 
different windows is relatively robust to the estimation method. Hence, these results suggest that the main pattern we observed in our simple OLS regression is robust both across the estimation method and the splitting year of the sample.

An alternative means of examining the role of accumulation forces, one which is commonly used in the literature, is to gather the effects of the investment rate and of population growth into one summary variable which captures a country's long-run capital intensity. In effect, from the standard law of motion of capital, one can readily derive a country's long-run capital-output ratio. The $\log$ of this ratio, which we will denote by $\mathcal{K}$, is given by the following relationship where $\delta$ is the rate of depreciation of capital and $\gamma$ is the rate of growth of labor augmenting technological progress.

$$
\mathcal{K} \equiv \log \left(\frac{k}{y}\right)=\log \left(\frac{\frac{i}{y}}{(1+n)(1+\gamma)-(1-\delta)}\right)
$$

To construct $\mathcal{K}$ we followed Mankiw et al. [1992] and set the annual depreciation rate of capital at $3 \%(\delta=0.03)$ and the rate of technological growth of $2 \%(\gamma=0.02)$. We checked the robustness of our results against alternative rates of depreciation and found no major differences.

In the first two columns of table 5 , we report IV estimates using $\mathcal{K}$ as regressor. The instruments used are those corresponding to the set $\mathrm{IV}^{\star}$. Two main comments are in order. First, the convergence parameter shares the same properties as those presented earlier. If we now focus on our accumulation variable $\mathcal{K}$, it shares the properties of our previous estimates of the investment rate and population growth. In particular, its size has more than tripled between the two subsamples shifting from 0.009 to 0.029 , and the stability test strongly indicates rejection.

By reducing the number of covariates in this way, we make it easier to consider results within sub-samples. In particular, we can now explore whether the observed instability of coefficients is being driven by primarily by rich or poor countries. To this end, we report in table 5 results based on splitting the sample of countries along the median level of incomes in $1960 .{ }^{22}$ As can be seen in Table 5, among the richer countries - those with an initial output per worker above the median of the distribution - convergence has actually declined slightly between periods, although not in a significant manner. Conversely, the coefficient on the accumulation forces is significantly different across the two sub-periods, with a change of the same order as the whole sample. If we now look at the poorest countries, we basically observe two phenomena. The first one is related to the convergence process. Convergence seems to have risen slightly between the two sub-samples, from no significant convergence between 1960 and 1978 to a convergence rate of -0.012 over the 1978-1998 period. More interestingly, a look at the accumulation parameter reveals that there has been a significant change in the importance of accumulation forces of a magnitude similar or higher than that observed in the whole sample. Therefore, the observed increase in the importance of traditional accumulation forces appears to have occurred rather

may have been a temporary phenomena that was concentrated in the 1978-96 period.

${ }^{22}$ The set of instrument is again $\mathrm{IV}^{\star}$. 
Table 5: Growth Regressions (Accumulation, IV)

\begin{tabular}{lcccccc}
\hline \hline & \multicolumn{2}{c}{ Total } & \multicolumn{2}{c}{$y_{1960}<\operatorname{med}\left(y_{1960}\right)$} & \multicolumn{2}{c}{$y_{1960} \geqslant \operatorname{med}\left(y_{1960}\right)$} \\
\cline { 2 - 7 } & $60-78$ & $78-98$ & $60-78$ & $78-98$ & $60-78$ & $78-98$ \\
\hline Const. & 0.121 & 0.121 & 0.060 & 0.114 & 0.176 & 0.075 \\
& $(0.021)$ & $(0.022)$ & $(0.046)$ & $(0.037)$ & $(0.039)$ & $(0.075)$ \\
$y_{0}$ & -0.011 & -0.014 & -0.003 & -0.012 & -0.017 & -0.010 \\
& $(0.002)$ & $(0.002)$ & $(0.006)$ & $(0.004)$ & $(0.004)$ & $(0.008)$ \\
$\mathcal{K}$ & 0.009 & 0.029 & 0.008 & 0.026 & 0.012 & 0.034 \\
& $(0.003)$ & $(0.004)$ & $(0.005)$ & $(0.005)$ & $(0.004)$ & $(0.008)$ \\
Wald & 0.154 & 1.981 & 0.483 & 0.124 & 7.190 & 3.286 \\
& {$[0.694]$} & {$[0.159]$} & {$[0.487]$} & {$[0.724]$} & {$[0.007]$} & {$[0.069]$} \\
\hline $\mathcal{Q}($ Total $)$ & 17.846 & {$[0.000]$} & 6.808 & {$[0.033]$} & 23.874 & {$[0.000]$} \\
$\mathcal{Q}\left(y_{0}\right)$ & 0.834 & {$[0.361]$} & 1.929 & {$[0.165]$} & 0.648 & {$[0.421]$} \\
$\mathcal{Q}(\mathcal{K})$ & 15.647 & {$[0.000]$} & 6.561 & {$[0.010]$} & 7.580 & {$[0.006]$} \\
\hline \hline
\end{tabular}

Note: Standard errors in parenthesis, $\mathrm{p}$-values in brackets. The variables used to instrument $\mathcal{K}$ are the initial level of (i/y), the average (c/y) over the sub-sample, and the average growth rate of population over the 15 first periods of the sub-sample. 75 observations. The line denote Wald reports the Wald test of the restriction implicit in the accumulation variable $\mathcal{K}$ that the coefficient of $(\mathrm{i} / \mathrm{y})$ is the same as that of $\log ((1+n)(1+\gamma)-(1-\delta))$.

uniformly across rich and poor countries.

Together, the results reported in tables 3 through 5 suggest that there may have been a major change in the determinants of growth across NSSA countries, whereby the importance of the two traditional growth factors emphasized in Solow [1956] — (i) the rate of investment in physical capital (or the savings rate) and (ii) population growth - having increased by a factor of almost 3 between the pre and post 1978 periods. In contrast, we find that the speed of convergence has remained rather stable over the period. Before turning to examining the relevance of these effects in terms of their role in changing distribution of output per worker, we first need to establish their robustness.

\subsection{Beyond Capital Accumulation: Checking Robustness}

In this section we report regression results that explore the robustness of our previous observation regarding the apparent increased importance of physical capital accumulation over the period 1978-98 versus 1960-78 period. More precisely, we first consider the effects of a possible misspecification error in the convergence process stemming from the omission of non-linear terms. We then address in substantial detail the important question of the role of education.

Nonlinear Convergence: We now address a potential source of bias that may explain our previous results: a mis-specification error underlying the overall convergence process. Implicit in our growth regression is the assumption that the transition dynamics are linear. However, it 
may be the case that basins of divergence and convergence have emerged over this period.

Table 6: Non-linear convergence

\begin{tabular}{lcccc}
\hline \hline & \multicolumn{2}{c}{ OLS } & \multicolumn{2}{c}{ IV } \\
\cline { 2 - 5 } & $60-78$ & $78-98$ & $60-78$ & $78-98$ \\
\hline Const. & 0.044 & 0.059 & 0.033 & 0.058 \\
& $(0.007)$ & $(0.007)$ & $(0.008)$ & $(0.008)$ \\
$n$ & -0.227 & -0.581 & -0.291 & -0.616 \\
& $(0.167)$ & $(0.178)$ & $(0.176)$ & $(0.181)$ \\
$i / y$ & 0.016 & 0.027 & 0.008 & 0.025 \\
& $(0.003)$ & $(0.004)$ & $(0.004)$ & $(0.004)$ \\
$y_{0}$ & -0.022 & -0.014 & -0.023 & -0.014 \\
& $(0.015)$ & $(0.015)$ & $(0.016)$ & $(0.015)$ \\
$y_{0}^{2}$ & -0.001 & -0.001 & -0.004 & -0.002 \\
& $(0.012)$ & $(0.012)$ & $(0.013)$ & $(0.012)$ \\
$y_{0}^{3}$ & 0.001 & -0.001 & 0.000 & -0.001 \\
& $(0.003)$ & $(0.003)$ & $(0.003)$ & $(0.003)$ \\
$R^{2}$ & 0.39 & 0.52 & - & - \\
\hline $\mathcal{Q}($ Total $)$ & 19.233 & {$[0.002]$} & 23.191 & {$[0.000]$} \\
$\mathcal{Q}\left(\left\{y_{0}^{j}\right\}_{j=1}^{3}\right)$ & 3.084 & {$[0.379]$} & 4.310 & {$[0.230]$} \\
$\mathcal{Q}(n, i / y)$ & 9.239 & {$[0.010]$} & 13.595 & {$[0.001]$} \\
\hline \hline
\end{tabular}

Note: Standard errors in parenthesis, p-values in brackets. WLS: Weights are given by the log of the population. IV: the variables used as instruments for $i / y$ and $n$ are the initial level of (i/y), the average (c/y) over the sub-sample, and the average growth rate of population over the 15 first periods of the subsample. 75 observations.

One simple way of addressing this possibility is to introduce higher order terms in the initial level of output in our growth equation. This allows the growth process to be different for countries starting from different initial levels. We introduce square and cubic terms in the initial (log) level of output to explore the relevance of this effect. ${ }^{23}$ In parallel to our previous results, we report in table 6 estimates using OLS, and IV. The set of instruments is $\mathrm{IV}^{\star}$. As can be seen from the table, non-linear terms are not found to be significant whatever the sub-period and whatever the estimation method. Accordingly, convergence does not exhibit any significant instability between the two sub-periods, while the accumulation forces continue to exhibit this instability. Hence, nonlinear convergence forces do not appear particularly relevant in our data. ${ }^{24}$

Education: Up to now, we have focused on whether the importance of physical capital accumulation may have changed over time. However, education, and the broader concept of human

\footnotetext{
${ }^{23}$ Note that for presentation purposes, the initial level of output is normalized by the 1960 US level for this exercise.

${ }^{24}$ In the absence of the investment rate and the rate of population growth in the regression, we do find some minor evidence of non-linearity.
} 
capital, is thought by most to be important contributing factor to growth. For instance, in the theory of endogenous growth, sustained growth is often the result of the accumulation of human capital over time (see Uzawa [1965] or Lucas [1988]). Furthermore, in their influential paper, Mankiw et al. [1992] propose an augmented version of the Solow growth model in which human capital - measured essentially by the proportion of the working age population in secondary school - enters the production function. Their results indicate that including both type of capital - physical and human - enables the neoclassical growth model to fit the data relatively better. Such a finding opened the route to a large number of studies that deliver more ambiguous conclusions concerning the exact role of education in the growth process (see Durlauf and Quah [1999] or Klenow and Rodrìguez-Clare [1997] for discussions). Therefore, without wanting to take a strong position on the overall importance of education in the growth process, we nevertheless want to examine (i) whether the effects of education have changed over time and (ii) whether controlling for educational investment (or human capital) affects our results regarding the change in importance of traditional growth factors. To this end, tables 7 through 9 report a set of regression where we introduced different measures of educational investment or human capital into our growth equations. ${ }^{25}$ Our first measure of educational investment is a weighted average of school enrollment for primary, secondary and tertiary degrees of education, as documented in Barro and Lee [1993]. ${ }^{26}$ This measure departs from the original Mankiw et al. [1992] specification of educational investment and rather follows Klenow and Rodrìguez-Clare [1997] who argue that focusing on this wider education class is more appropriate. In table 7 we report estimates for both OLS and IV estimation. Two sets of instruments are investigated. The first one consists of our $\mathrm{IV}^{\star}$ set and is used to instrument both the investment rate and the rate of population growth. The results from this exercise are given under the heading IV1 in table 7 . The second set augments $\mathrm{IV}^{\star}$, as to allow us to instrument our educational investment variable, by including the number of years of schooling at the beginning of the period. The latter is aimed at mitigating potential measurement error in the school enrollment rate data.

Two main conclusions can be drawn from table 7. First of all, the change in importance of the traditional growth factors over the two samples is not at all diminished when we include educational investment into our equation. In effect, rather than diminishing the change in coefficients of the investment rate and on population growth, the introduction of education actually magnifies it slightly. Second, in none of the three cases do we find the importance of educational investment to have increased over the two sub-samples. In fact, the estimates suggest that there may have been a decrease. Although the results in this table do not support a

\footnotetext{
${ }^{25}$ The education data are discussed more extensively in appendix A. Note that because of data availability problems, we loose 7 countries from our sample.

${ }^{26}$ The weights for calculating this measure of educational investment correspond to the average number of years spent in each degree

$$
E d u c \equiv \log \left(\frac{6 \times E^{P}+6 \times E^{S}+4 \times E^{T}}{16}\right)
$$
}

where $E^{P}, E^{S}$ and $E^{T}$ denote respectively the enrollment rate in the primary, secondary and tertiary sector. 
Table 7: Education (I)

\begin{tabular}{lcccccc}
\hline \hline & \multicolumn{2}{c}{ OLS } & \multicolumn{2}{c}{ IV1 } & \multicolumn{2}{c}{ IV2 } \\
\cline { 2 - 7 } & $60-78$ & $78-98$ & $60-78$ & $78-98$ & $60-78$ & $78-98$ \\
\hline Const. & 0.218 & 0.216 & 0.197 & 0.218 & 0.197 & 0.249 \\
& $(0.032)$ & $(0.036)$ & $(0.033)$ & $(0.036)$ & $(0.036)$ & $(0.046)$ \\
$y_{0}$ & -0.017 & -0.014 & -0.015 & -0.014 & -0.015 & -0.017 \\
& $(0.003)$ & $(0.003)$ & $(0.003)$ & $(0.003)$ & $(0.003)$ & $(0.004)$ \\
$n$ & -0.082 & -0.710 & -0.117 & -0.736 & -0.117 & -0.709 \\
& $(0.164)$ & $(0.159)$ & $(0.171)$ & $(0.161)$ & $(0.171)$ & $(0.164)$ \\
$i / y$ & 0.014 & 0.029 & 0.006 & 0.030 & 0.006 & 0.028 \\
& $(0.003)$ & $(0.004)$ & $(0.004)$ & $(0.005)$ & $(0.004)$ & $(0.005)$ \\
Educ. & 0.010 & -0.002 & 0.015 & -0.004 & 0.015 & 0.008 \\
& $(0.006)$ & $(0.009)$ & $(0.006)$ & $(0.009)$ & $(0.008)$ & $(0.014)$ \\
\hline $\mathcal{Q}$ (Total) & 24.275 & {$[0.000]$} & 28.970 & {$[0.000]$} & 28.844 & {$[0.000]$} \\
$\mathcal{Q}\left(y_{0}\right)$ & 0.342 & {$[0.559]$} & 0.053 & {$[0.818]$} & 0.152 & {$[0.697]$} \\
$\mathcal{Q}(n, i / y)$ & 18.934 & {$[0.000]$} & 24.660 & {$[0.000]$} & 19.879 & {$[0.000]$} \\
$\mathcal{Q}$ (Educ.) & 1.488 & {$[0.223]$} & 3.100 & {$[0.078]$} & 0.220 & {$[0.639]$} \\
\hline \hline
\end{tabular}

Note: Standard errors in parenthesis, $\mathrm{p}$-values in brackets. IV1: the variables used to instrument $i / y$ and $n$ are the initial level of (i/y), the average (c/y) over the sub-sample, and the average growth rate of population over the 15 first periods of the sub-sample. IV2: the set of instruments of IV1 is completed by the years of schooling to also instrument the education variable. 68 observations.

strong effect of education investment on growth - at least not in the frequency of two decades ${ }^{27}$ - this may have arisen because of measurement error. In effect, as we see in the last column, the negative effect of educational investment observed in the 1978-98 period in the first columns disappears when we instrument educational investment with the number of years of education.

To explore the appropriateness of our measure of educational investment, in table 8 we report a set of regression using two alternative measures to control for educational differences. The first one, P\&S, still refers to educational investment as it is a weighted average of primary and secondary enrollment rates, where the weights are the duration (DURP and DURS) in years of each of these two education stages in the different countries as provided in Barro and Lee [1993]. ${ }^{28}$ The second variable, Years, is a direct measure of the stock of human capital per capita as it corresponds to the average schooling in the total population over 25 also from Barro and Lee [1993]. The results in table 8 are essentially identical to those found in table 7 , that is,

\footnotetext{
${ }^{27}$ This result is in the lines of that obtained by Benhabib and Spiegel [1994] who also find a insignificant and wrong signed effect of education investment on GDP growth. However it contrasts with the findings of Krueger and Lindhal [2001] who point to a positive effect of education on output growth. It should nevertheless be noted that the strong positive effect of education on growth obtained in Krueger and Lindhal [2001] only holds when they abstract from physical capital (see table 1 p. 1112 in Krueger and Lindhal [2001]). As soon as physical capital is brought back into the regression, education changes are not significant.

${ }^{28}$ The measure is

$$
\mathrm{P} \& \mathrm{~S} \equiv \log \left(\frac{D U R P \times E^{P}+D U R S \times E^{S}}{D U R P+D U R S}\right)
$$
}


the importance of traditional growth factors appear to have increased while the importance of education has stayed the same or possibly decreased.

Table 8: Education II

\begin{tabular}{lcccccc}
\hline \hline & \multicolumn{2}{c}{ P\&S (IV1) } & \multicolumn{2}{c}{ P\&S (IV2) } & \multicolumn{2}{c}{ Years (IV1) } \\
\cline { 2 - 7 } & $60-78$ & $78-98$ & $60-78$ & $78-98$ & $60-78$ & $78-98$ \\
\hline Const. & 0.192 & 0.218 & 0.191 & 0.245 & 0.174 & 0.234 \\
& $(0.032)$ & $(0.034)$ & $(0.040)$ & $(0.040)$ & $(0.031)$ & $(0.031)$ \\
$y_{0}$ & -0.015 & -0.014 & -0.015 & -0.017 & -0.014 & -0.016 \\
& $(0.003)$ & $(0.003)$ & $(0.004)$ & $(0.004)$ & $(0.003)$ & $(0.003)$ \\
$n$ & -0.146 & -0.732 & -0.146 & -0.721 & -0.129 & -0.710 \\
& $(0.170)$ & $(0.159)$ & $(0.170)$ & $(0.161)$ & $(0.171)$ & $(0.161)$ \\
$i / y$ & 0.007 & 0.030 & 0.007 & 0.028 & 0.008 & 0.029 \\
& $(0.004)$ & $(0.005)$ & $(0.004)$ & $(0.005)$ & $(0.004)$ & $(0.004)$ \\
Educ. & 0.015 & -0.005 & 0.015 & 0.009 & 0.006 & 0.002 \\
& $(0.006)$ & $(0.010)$ & $(0.008)$ & $(0.015)$ & $(0.003)$ & $(0.004)$ \\
\hline $\mathcal{Q}$ (Total) & 28.554 & {$[0.000]$} & 28.489 & {$[0.000]$} & 28.072 & {$[0.000]$} \\
$\mathcal{Q}\left(y_{0}\right)$ & 0.041 & {$[0.839]$} & 0.232 & {$[0.630]$} & 0.241 & {$[0.624]$} \\
$\mathcal{Q}(n, i / y)$ & 24.182 & {$[0.000]$} & 18.653 & {$[0.000]$} & 22.829 & {$[0.000]$} \\
$\mathcal{Q}$ (Educ.) & 3.347 & {$[0.067]$} & 0.112 & {$[0.737]$} & 0.593 & {$[0.441]$} \\
\hline \hline
\end{tabular}

Note: Standard errors in parenthesis, $\mathrm{p}$-values in brackets. All regressions are estimated by instrumental variables. IV1: the variables used to instrument $i / y$ and $n$ instruments are the initial level of $(\mathrm{i} / \mathrm{y})$, the average $(\mathrm{c} / \mathrm{y})$ over the sub-sample, and the average growth rate of population over the 15 first periods of the sub-sample. IV2: the set of instruments are those of IV1 completed by the years of schooling to instrument the education variable. 68 observations.

As an alternative way of examining the role of education, we construct a long run human capital intensity variable as we did for physical capital. This variable, which we denote by $\mathcal{H}$, is built using educational investment rate data $(E)$ as follows. ${ }^{29}$

$$
\mathcal{H} \equiv \log \left(\frac{E}{(1+n)(1+\gamma)-(1-\delta)}\right)
$$

As for the physical capital accumulation variable, we set $\gamma+\delta=0.05$. Table 9 reports a set of OLS and IV regressions using both $\mathcal{K}$ and $\mathcal{H}$ as regressors. The sets of instruments are those associated with $\mathrm{IV}^{\star}$ and then augmented in include the average years of education to instrument $\mathcal{H}$. Once again we find that the importance of education has not increased while the importance of physical investment appears to have increase by at least an order of 3 .

One last way of assessing the role of education in the growth process is two split the sample of countries in two depending on the average level of education in a country in 1960 . Then by running regressions for each of the sub-samples, we can gauge whether the apparent effects of the increased importance of capital accumulation may be limited to higher educated countries. Table

\footnotetext{
${ }^{29}$ The measure of educational investment we use is the same weighted average of enrolment rates as in table 8.
} 
Table 9: Education (III)

\begin{tabular}{lcccccc}
\hline \hline & \multicolumn{2}{c}{ OLS } & \multicolumn{2}{c}{ IV1 } & \multicolumn{2}{c}{ IV2 } \\
\cline { 2 - 7 } & $60-78$ & $78-98$ & $60-78$ & $78-98$ & $60-78$ & $78-98$ \\
\hline Const. & 0.149 & 0.128 & 0.131 & 0.130 & 0.135 & 0.142 \\
& $(0.022)$ & $(0.023)$ & $(0.023)$ & $(0.023)$ & $(0.024)$ & $(0.024)$ \\
$y_{0}$ & -0.016 & -0.016 & -0.014 & -0.016 & -0.014 & -0.019 \\
& $(0.003)$ & $(0.003)$ & $(0.003)$ & $(0.003)$ & $(0.003)$ & $(0.004)$ \\
$\mathcal{K}$ & 0.013 & 0.030 & 0.006 & 0.031 & 0.006 & 0.028 \\
& $(0.004)$ & $(0.004)$ & $(0.004)$ & $(0.005)$ & $(0.004)$ & $(0.005)$ \\
$\mathcal{H}$ & 0.007 & 0.005 & 0.013 & 0.003 & 0.012 & 0.016 \\
& $(0.006)$ & $(0.008)$ & $(0.006)$ & $(0.008)$ & $(0.007)$ & $(0.010)$ \\
$R^{2}$ & 0.36 & 0.56 & - & - & - & - \\
\hline $\mathcal{Q}($ Total $)$ & 19.549 & {$[0.000]$} & 25.378 & {$[0.000]$} & 28.605 & {$[0.000]$} \\
$\mathcal{Q}\left(y_{0}\right)$ & 0.000 & {$[0.991]$} & 0.087 & {$[0.768]$} & 1.217 & {$[0.260]$} \\
$\mathcal{Q}(\mathcal{K})$ & 10.320 & {$[0.001]$} & 16.824 & {$[0.000]$} & 12.412 & {$[0.000]$} \\
$\mathcal{Q}(\mathcal{H})$ & 0.062 & {$[0.803]$} & 1.050 & {$[0.305]$} & 0.133 & {$[0.715]$} \\
\hline \hline
\end{tabular}

Note: Standard errors in parenthesis, $\mathrm{p}$-values in brackets. IV1: the variables used in instrument $\mathcal{K}$ are the initial level of (i/y), the average $(\mathrm{c} / \mathrm{y})$ over the sub-sample, and the average growth rate of population over the 15 first periods of the sub-sample. IV2: the set of instruments is that of IV1 completed by the years of schooling to instrument $\mathcal{H}$. 68 observations.

10 reports the results for such an experiment. We re-adopt the parsimonious specification that only involves the initial level of (log) output per worker and our physical capital accumulation variable, $\mathcal{K}$, for this exercise since the degrees of freedom are more limited. We split the sample into two groups of countries: those for which the number of years of schooling is higher than the median of the distribution in 1960, and the rest of the countries. The estimation is carried out using IV where the set of instrumental variables corresponds to IV ${ }^{\star}$. Two main results stand out when we look at the table. First, stability tests reveal that the convergence process has remained significantly unchanged in highly educated countries (with a p-value of about 0.6) and at a level comparable to that obtained in our earlier estimations. Conversely, low educated countries have experienced a large and significant ( $\mathrm{p}$-value of 0.03 ) increase in the convergence rate. Second and more interestingly, the importance of physical capital accumulation seems to have undergone a significant change in both sets of countries, as stability tests indicate the null of a stable coefficient is strongly rejected by the data. It is interesting to note that the change appears to have been slightly greater for the lower educated countries.

As can be seen from all the preceding experiments, our main findings - (i) a steady convergence and (ii) an increase in the importance of traditional forces of accumulation - are robust to many specification changes and estimation methods. Accordingly, we will use the estimated growth process from our benchmark OLS regression in table 3 in what follows to decompose the changes 
Table 10: Accumulation and Education (IV)

\begin{tabular}{lcccccc}
\hline \hline & \multicolumn{2}{c}{ Total } & \multicolumn{2}{c}{$H_{1960}<\operatorname{med}\left(H_{1960}\right)$} & \multicolumn{2}{c}{$H_{1960} \geqslant \operatorname{med}\left(H_{1960}\right)$} \\
\cline { 2 - 7 } & $60-78$ & $78-98$ & $60-78$ & $78-98$ & $60-78$ & $78-98$ \\
\hline Const. & 0.125 & 0.131 & 0.077 & 0.148 & 0.170 & 0.130 \\
& $(0.024)$ & $(0.023)$ & $(0.041)$ & $(0.037)$ & $(0.033)$ & $(0.035)$ \\
$y_{0}$ & -0.011 & -0.015 & -0.005 & -0.017 & -0.017 & -0.015 \\
& $(0.003)$ & $(0.003)$ & $(0.005)$ & $(0.004)$ & $(0.004)$ & $(0.004)$ \\
$\mathcal{K}$ & 0.010 & 0.033 & 0.005 & 0.032 & 0.018 & 0.030 \\
& $(0.004)$ & $(0.004)$ & $(0.005)$ & $(0.006)$ & $(0.005)$ & $(0.005)$ \\
Wald & 0.000 & 2.934 & 0.178 & 0.876 & 0.285 & 1.718 \\
& {$[0.997]$} & {$[0.086]$} & {$[0.673]$} & {$[0.349]$} & {$[0.593]$} & {$[0.189]$} \\
\hline $\mathcal{Q}($ Total $)$ & 26.816 & {$[0.000]$} & 16.186 & {$[0.000]$} & 5.339 & {$[0.069]$} \\
$\mathcal{Q}\left(y_{0}\right)$ & 1.349 & {$[0.245]$} & 4.517 & {$[0.034]$} & 0.233 & {$[0.629]$} \\
$\mathcal{Q}(\mathcal{K})$ & 22.478 & {$[0.000]$} & 15.806 & {$[0.000]$} & 3.203 & {$[0.074]$} \\
\hline \hline
\end{tabular}

Note: Standard errors in parenthesis, p-values in brackets. All regression estimated by IV. The variables used to instrument $\mathcal{K}$ are the initial level of (i/y), the average (c/y) over the sub-sample, and the average growth rate of population over the 15 first periods of the sub-sample. The lines denote Wald reports the Wald test of the restriction implicit in the accumulation variable $\mathcal{K}$ that the coefficient infront of $(\mathrm{i} / \mathrm{y})$ is the same as that affecting $\log ((1+n)(1+\gamma)-(1-\delta))$.

in the distribution of output per worker. Results related to using other estimates are presented in the appendix.

\section{Implementing the decomposition}

In this section we decompose the observed changes in the distribution of output per worker over the period 1960-78 using the framework presented in section 2. As suggested in the results of the last section, part of the explanation for the observed changes in the shape of the distribution over this period may be due to the observed change in the importance of the traditional forces of the accumulation process - i.e. changes in the $\beta$ s associated with the rate of investment and the effect of population growth. Figure 5 reports the decomposition of changes in the distribution for different potential effects using our benchmark OLS regression as our estimate of the growth process (results using IV estimates are reported in the appendix, figure 9). Each panel reports three pieces of informations. The grey line corresponds to the initial distribution of output per worker as observed in 1960, the plain dark line corresponds to the distribution of 1998 output per worker, and the dashed dark line is the distribution of the 1998 output per worker "corrected" for the effect that we examine. More precisely, the last distribution is based on each counterfactual experiment described in section 2. For example, when we look at the effects of a change in the coefficients of population growth and the investment/output ratio, the distribution we report is that obtained using equation (7). This counterfactual experiment 
actually furnishes an answer to the question: what would the output per worker distribution in 1998 have been had the coefficients in the growth process remained at their values from the earlier period? This graphical analysis is complemented with a quantitative assessment of the observed changes in tables 11 and 12 which report, respectively, the same decomposition in terms of the (20-80, 25-75 and 30-70) percentile differences and the mass-around-the-mean statistic at $\pm 0.6,0.7$ and $0.8 \log -$ points around the mean.

Figure 5: Decomposing the observed changes in the distributions

(a) Observables $\left(\mathrm{y}_{0}\right)$

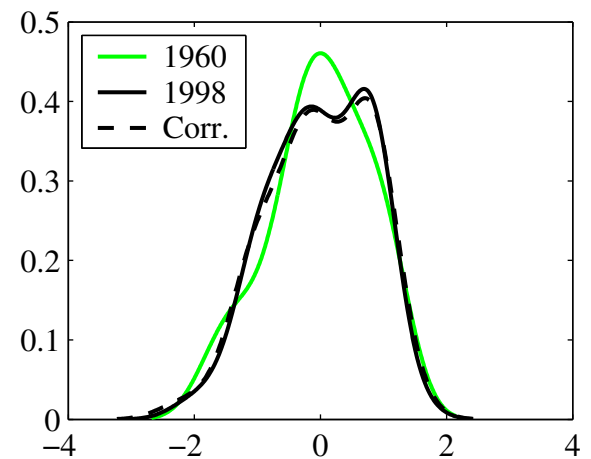

(c) Distribution $(\mathrm{n}, \mathrm{i} / \mathrm{y})$

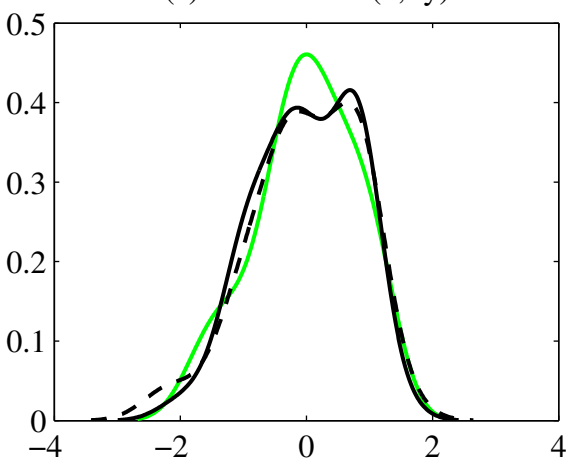

(e) Observables $(\mathrm{n}, \mathrm{i} / \mathrm{y})$

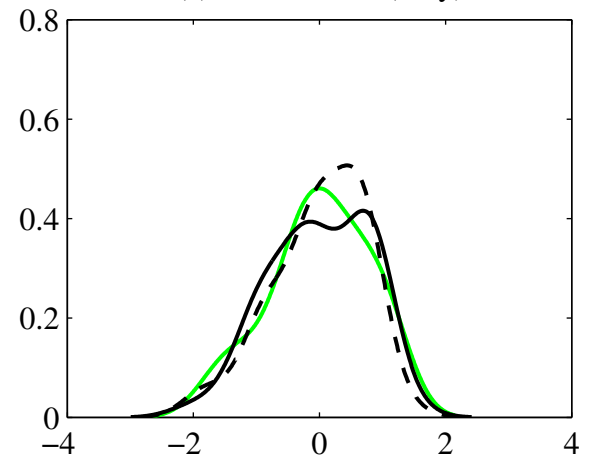

(b) Coefficients $\left(\beta_{\mathrm{y}}^{78-98}=0\right)$

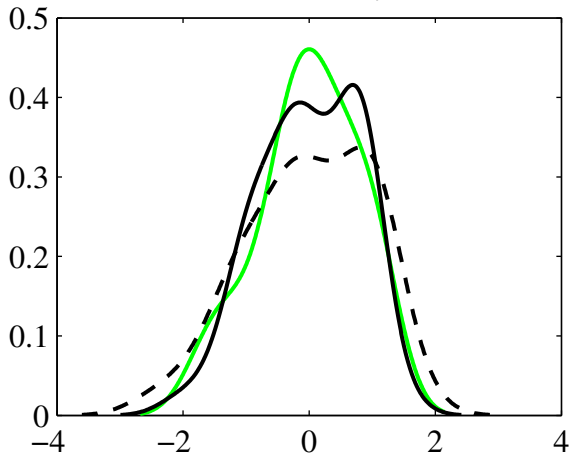

(d) Coefficients $(\mathrm{n}, \mathrm{i} / \mathrm{y})$

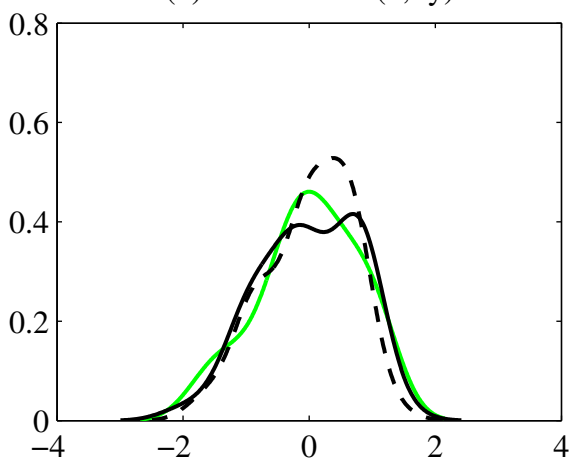

(f) Unobservables

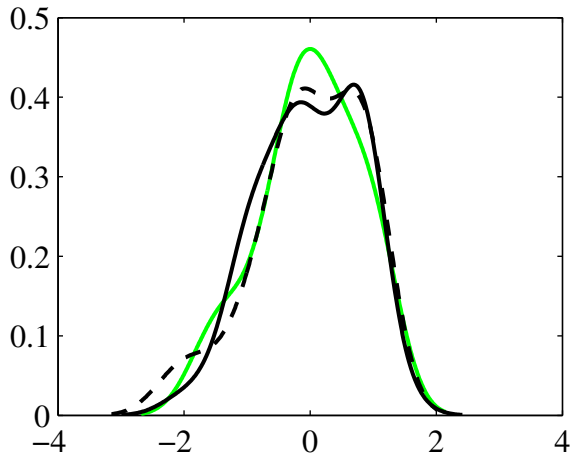

Panel (a) of figure 5 reports the decomposition obtained when we control for the effects due to a change in convergence forces (this amounts to building the counterfactual 1998 output per worker $\left.y_{i}^{\beta_{y} y^{60}}=y_{i}^{98}+20 \times\left(y_{i}^{60} \beta_{y}^{60-78}-y_{i}^{78} \beta_{y}^{78-98}\right)\right)$. As clearly indicated by the figure, 
Table 11: Percentiles

\begin{tabular}{lcccccccc}
\hline \hline perc. & $98-60$ & $98-78$ & $98-y^{R}$ & $\beta_{n, i / y}$ & $\Delta X_{n, i / y}$ & Obs. $_{n, i / y}$ & ${\text { Obs. } y_{0}}_{c}$ & $\varepsilon$ \\
\hline $20-80$ & 0.207 & 0.314 & 0.361 & 0.194 & 0.130 & 0.148 & -0.049 & 0.145 \\
$25-75$ & 0.265 & 0.376 & 0.373 & 0.264 & 0.035 & 0.305 & 0.065 & 0.224 \\
$30-70$ & 0.197 & 0.216 & 0.320 & 0.370 & -0.053 & 0.226 & -0.035 & 0.060 \\
\hline Average & 0.223 & 0.302 & 0.351 & 0.276 & 0.037 & 0.226 & -0.006 & 0.143 \\
\hline \hline
\end{tabular}

Table 12: Mass around the mean

\begin{tabular}{lcccccccc}
\hline \hline$\Delta$ & $98-60$ & $98-78$ & $98-y^{R}$ & $\beta_{n, i / y}$ & $\Delta X_{n, i / y}$ & Obs. $\cdot, i / y_{1}$ & ${\text { Obs. } y_{0}}_{c}$ & $\varepsilon$ \\
\hline 0.60 & -10.667 & -14.667 & -12.000 & -6.667 & -4.000 & -4.000 & 0.000 & -2.667 \\
0.70 & -12.000 & -17.333 & -14.667 & -10.667 & -4.000 & -14.667 & 1.333 & -6.667 \\
0.80 & -5.333 & -13.333 & -12.000 & -16.000 & 1.333 & -10.667 & 2.667 & -4.000 \\
\hline Average & -9.333 & -15.111 & -12.889 & -11.111 & -2.222 & -9.778 & 1.333 & -4.445 \\
\hline \hline
\end{tabular}

changes in the convergence forces do not explain much of the changes in the decomposition, as the counterfactual distribution remains very close to the 1998 distribution. This should have been expected from our preliminary econometric analysis and the results in terms of observed distribution of output per worker. Indeed, the stability tests together with the rolling regressions from the previous section all suggested that the convergence parameter remained steady across the two sub-periods. In addition, the 1978 distribution output per worker was found to be close to that for 1960. This graphical appraisal is confirmed by the quantitative results reported in tables 11 and 12. For instance, the changes in the interquartile range between 1960 and 1998 that are accounted for by changes in convergence forces is 0.065 , to be compared to the 0.265 in the data. Likewise, convergence does not account for changes in the mass lying between 0.6 and 0.8 away from the mean of the distribution. However, this does not mean that convergence played no role in designing the shape of the distribution. In order to illustrate this, we report in panel (b) of figure 5 the distribution what would have been obtained had convergence had totally vanished over the second sub-period $\left(\beta_{y}^{78-98}=0\right)$. As can be seen from the figure, had convergence disappeared, the distribution would have widened substantially with most of the phenomenon taking place in the tails of the distribution. Therefore, we are not arguing that the role of convergence was irrelevant over this period, but instead that changes in this force does not help to account for the twin-peaks phenomenon.

We now turn our attention to the accumulation forces which we found to be unstable between the two periods. Let us first focus on the effects of the observed changes in the distribution of the population rate of growth and the investment/output ratio. As can be seen from panel (c) of figure 5, changes in the distribution of the accumulation forces do not explain much of the changes in the distribution as the counterfactual distribution built using equation (5) is close to 
the actual 1998 distribution. This result is unsurprising given figure 6 which reports the 1960-78 and 1978-98 distributions of the investment/output ratio and the population rate of growth. The distribution of these two variables remained rather stable across the two sub-periods, with the distribution of the investment rate becoming - if anything - more peaked in the second period. This explains why we should not expect a large impact from this component. This graphical

Figure 6: Distribution of Accumulation Forces
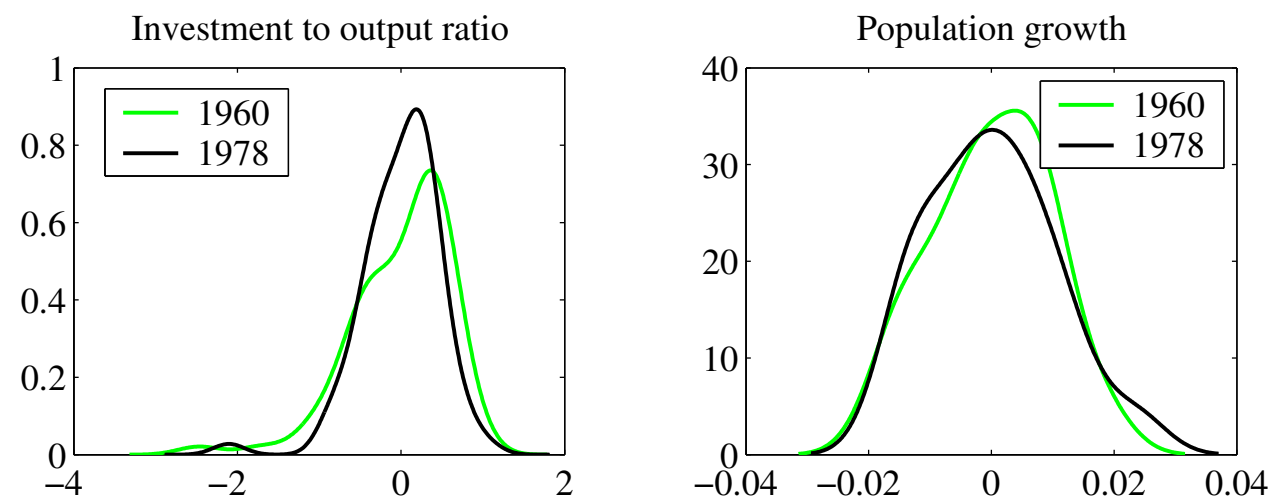

appraisal is confirmed by the inspection of columns $\Delta X_{n, i / y}$ of tables 11 and 12 , which indicate for instance that out of the 0.265 change in the interquartile range between 1960 and 1998 only 0.035 are accounted for by a change in the distribution of the traditional accumulation forces.

Hence if the explanation of the change in the distributions is to be found in the forces associated with physical capital accumulation, it should be found in a variation in the coefficients. This case is examined in panel (d) of figure 5 with the counterfactual experiment based on equation (7). The figure shows that changes in the coefficients affecting population growth and the investment/output ratio contribute a great deal to the phenomenon. The first feature that jumps out of panel (d) is that correcting for the instability in the accumulation coefficients totally undoes the twin-peaks phenomenon. In other words, the twin-peaks phenomenon does not seem to be the by-product of a change in the convergence forces, but rather by a change in importance of physical capital accumulation. Beyond the effects in terms of bi-modality, changes in these coefficients clearly had an effect on the spread of the distribution. Setting the coefficients to their 1960-78 values generates a more compressed counterfactual distribution, indicating that the large change in these coefficients between periods contributed to the widening of the distribution.

The qualitative appraisal based on the figures is confirmed by the results in column $\beta_{n, i / y}$ of tables 11 and 12. For example, out of the 0.265 change in the interquartile range that took place between 1960 and 1998, the change in the coefficient of the two accumulation forces accounts for 0.264 . The same pattern is found for the 20-80 percentile difference, as a change of 0.194 is predicted by the instability of the coefficients to be compared to the 0.207 found in the data. There actually is tendency to over-explain the phenomenon when we look at the 30-70 percentile difference, as this coefficient effect is almost twice that observed in the data. Very 
similar results are obtained when we look at the mass around the mean. For example, when we deviate by 0.6 log-points from the mean, the change in the $\beta_{n, i / y}$ predicts a decrease in mass of 11 percent between 1960 and 1998, while the mass in the corresponding window of the data changed by 7 percentage points. Likewise, for a deviation of \pm 0.7 , the instability in the coefficients accounts for a drop of about 11 percentage points compared to the almost 12 found in the actual distribution. In other words, the changes in the magnitude of the accumulation forces appear to have contributed enormously to the observed changes in the shape of the distribution.

Overall changes in the accumulation forces, that is, effects due to both changes in the coefficients and changes in the distributions of $i / y$ and $n$, actually slightly over-explain the observed modification in the shape of the distribution of output per worker. This is shown in Obs. ${ }_{n, i}$ in tables 11 and 12 and in panel (e) of figure 5. However, when we examine results in terms of changes between 1978 and 1998, the accumulation forces explain the observed change almost exactly, with little over- explanation. For example out of the 0.376 observed change in the interquartile range between 1978 and 1998, the changes due to the total of accumulation forces (both $\beta$ and the distribution of $X \mathrm{~s}$ ) is 0.305 . Furthermore, on average the changes in the percentile differences predicted by the variation of the accumulation forces was 0.312 to be compared to the 0.226 observed in the data for the period 1978-1998. Likewise, on average the mass around the mean has dropped by 15 percentage points, out of which 10 are predicted by the changes in the traditional growth factor.

Our point is not to deny any role to other potential factors in affecting growth, but rather to emphasize the potentially very important role played by traditional growth factors in reshaping the world distribution of output per worker since 1978. Our framework suggested, as seen in panel (f) of figure 5, that omitted or residual factors did not play a very decisive role in this process. Indeed, as can be seen from the figure, controlling for unobservable components leaves the distribution of 1998 output per worker almost unchanged. Such a finding is confirmed by the last columns of tables 11 and 12 which indicate that the contribution of unobservable components to the explanation of the changed in the percentile differences or the mass-aroundthe-mean was much lower than the contribution due to changes in the importance of population growth and the investment rate. This observation is especially surprising given that, by adopting a very parsimonious specification of the growth process, we could have expected the residual component to play a large role.

Our approach in tables 11 and 12 has been to present the effects of different forces $(\beta \mathrm{s}, X \mathrm{~s}$, unobservables...) one at a time - altering only that component while leaving the others at their 1978-98 values. This approach has the attractive property of treating each force symmetrically. However, a more common means of reporting results of decompositions is to sequentially combine effects such that the end results mechanically add up to explain the relevant change in distribution. Thus, most decompositions exercises typically change first, say, $\mathrm{X}$ to its alternative value, then $\mathrm{X}$ and $\beta$, etc... In table 13 and 14 we report results in a manner consistent with this 
adding-up reasoning and in a manner that recognizes that such results are not independent of the order of sequencing. Since our claim is that changes in the coefficients on population growth and investment rate explain most of the change in distribution, we choose the following two sequences to back this claim. First, we put the change in the coefficients on $n$ and $i / y$ first in the ordering (ordering I). This effectively means that all the other forces - which we denote by $\mathcal{R}$ - act as a residual, capturing whatever is left of the change between $y^{98}$ and $y^{R}$ (where $y^{R}$ controls for all effects) after accounting for the effects of $n$ and $i / y$. Note that the set of $\mathcal{R}$ forces correspond to the sum of effects due to unobservable components, changes in convergence forces and changes in the distributions of variables. Second, we implement the reverse ordering, where we begin be assessing the role of all the $\mathcal{R}$ forces, and leave the effects of the coefficients on $n$ and $i / y$ to be determined residually (ordering II). As can be seen in tables 13 and 14, regardless of the ordering the result is quite clear: changes in the coefficients on $n$ and $i / y$ explain all (or too much) of the hollowing-out process as captured by our reference percentile differences and the mass-around-the-mean statistics.

Table 13: Percentiles II

\begin{tabular}{lcccccc}
\hline \hline & & \multicolumn{2}{c}{ Ordering I } & & \multicolumn{2}{c}{ Ordering II } \\
\cline { 3 - 4 } \cline { 6 - 7 } perc. & $98-y^{R}$ & $\beta_{n, i / y}$ & $\mathcal{R}$ & & $\mathcal{R}$ & $\beta_{n, i / y}$ \\
\hline $20-80$ & 0.361 & 0.194 & 0.167 & & -0.048 & 0.409 \\
$25-75$ & 0.373 & 0.264 & 0.109 & & -0.082 & 0.455 \\
$30-70$ & 0.320 & 0.370 & -0.050 & & -0.098 & 0.418 \\
\hline Average & 0.351 & 0.276 & 0.075 & & -0.076 & 0.427 \\
\hline \hline
\end{tabular}

Table 14: Mass around the mean

\begin{tabular}{lcccccc}
\hline \hline & & \multicolumn{2}{c}{ Ordering I } & & \multicolumn{2}{c}{ Ordering II } \\
\cline { 3 - 4 } \cline { 6 - 7 }$\Delta$ & $98-y^{R}$ & $\beta_{n, i / y}$ & $\mathcal{R}$ & & $\mathcal{R}$ & $\beta_{n, i / y}$ \\
\hline 0.60 & -12.000 & -6.667 & -5.333 & & 0.000 & -12.000 \\
0.70 & -14.667 & -10.667 & -4.000 & & -4.000 & -10.667 \\
0.80 & -12.000 & -16.000 & 4.000 & & -4.333 & -7.667 \\
\hline Average & -12.889 & -11.111 & -1.778 & & -2.777 & -10.111 \\
\hline \hline
\end{tabular}

In light of the all preceding results, we infer that most of the observed changes in the distribution of output per worker between 1960 (or 1978) and 1998 - in particular its widening in the interquartile range area and the twin-peaks phenomenon - is related to an increase in importance of traditional accumulation forces. More particularly, this change resulted from a change in the form of the process (coefficients) rather than a modification in the distribution of these forces. 


\section{Bringing back sub Saharan Africa}

In the previous section, we focussed exclusively on NSSA countries. We now want to extend our sample to include the sub-Saharan African countries and examine how this affects our interpretation of the role of different observable and unobservable factors is explaining the changes in the distribution.

\subsection{Still the twins?}

Figure 7 reports the empirical distribution of (log) output per worker in years 1960, 1978 and 1998 for all countries in the Penn World Tables 6.0 (106 countries) for which data is available. ${ }^{30}$ We will refer to this larger set of countries as the "world". As in section 1, the distributions

Figure 7: Distribution of output per worker

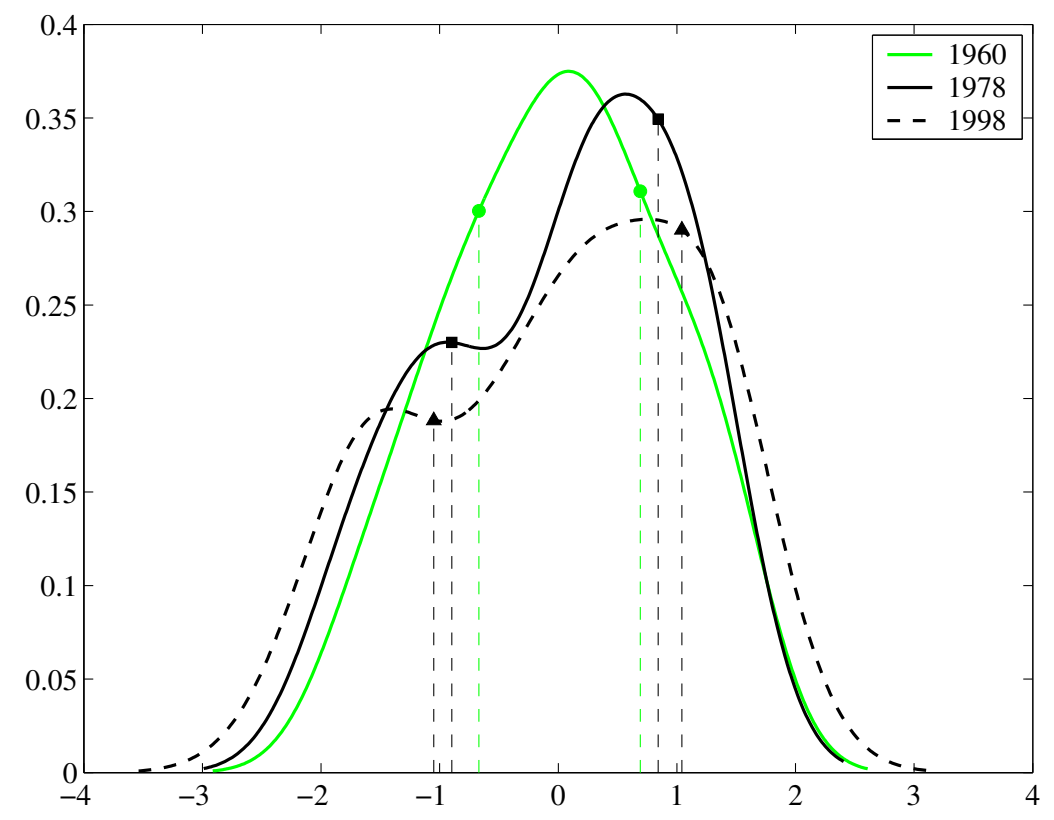

are estimated using a Gaussian kernel density estimator and are centered around their mean. Figure 7 also reports the points in the distribution associated with the interquartile ranges in 1960, 1978 and 1998. ${ }^{31}$ Several comments are in order. First and foremost, it appears that, as in our restricted sample, the shape of the distribution has changed considerably over time. As before, the distribution of output per worker is uni-modal and almost normal in 1960. As time has passed, mass shifted away from the center, creating two new modes. While the shape in 1998 is bi modal, it is also quite different relative to the NSSA sample. In effect, instead of characterizing the 1998 distribution for this wider set of countries as twin-peaked, it may be

\footnotetext{
${ }^{30}$ We include all countries with at most two years of missing data between 1960 and 1998.

${ }^{31}$ The points of the interquartile range are calculated from the raw data and not from the kernel estimates of the density function.
} 
more appropriately called hump-shaped. Moreover, there is another major difference relative to our earlier observation, which is that the hump-shape is already present by 1978 while the twin peaks in the NSSA sample only emerged after 1978. In what follows, we will argue that there were two distinct phenomena going on in the world distribution. First, in the 1960-1978 period, sub-Saharan African countries experienced particularly bad draws in residual factors that is factors not associated with either human or physical capital accumulation - and these bad draws created the hump-shape observed in 1978. Secondly, after 1978, the growth process changed in a manner that favoured countries which favoured physical capital deepening and this again explains most of the change in distribution observed from 1978 to 1998 (without a need to refer to particular bad draws for sub-Saharan Africa in the later period). In what follows, we substantiate this claim.

\subsection{Reexamining changes in the growth process}

As in the previous section, our goal is to document the forces underlying the observed changes in the world distribution of the output per worker over the period 1960-98. A preliminary step in our argument is therefore to examine whether the instability in the growth process documented for our restricted sample holds when sub-Saharan African countries are included. Table 15 reports a series of estimates for the growth process over the period 1960-78 versus 1978-98 using ordinary least squares (OLS), weighted least squares (WLS) and instrumental variables (IV). When WLS are performed, each country is weighted according to the logarithm of its average population. When an IV procedure is used, we instrument the investment rate and population growth using the $\mathrm{IV}^{\star}$ set of instruments. Note that we also include a sub Saharan Africa dummy in order to capture potential region specific effects. However, it is worth noting that the exclusion of this dummy variables does not significantly affect the other estimates in the table.

We focus first on the OLS results. Not surprisingly, the sub Saharan Africa dummy is significantly negative in both sub-periods. The convergence parameter - the coefficient associated to $y_{0}$ - is very close to that obtained in section 3.1. Furthermore, just like in our restricted

sample, the estimates of convergence remained rather stable over the two sub-periods, as the stability test statistic $\left(\mathcal{Q}\left(y_{0}\right)\right.$ in the table) does not permit rejection of the stability hypothesis at conventional significance levels $(\mathrm{p}-$ value $=0.543)$. Once again, the main change that emerges from the data relates to the traditional forces of growth. Indeed, the results reported in the two first columns of table 15 suggest that the magnitude of the coefficients affecting the rate of growth of the labour force and the investment/output ratio increased in a manner similar to that observed in our restricted sample. The coefficient measuring the impact of population growth on the growth process was not significant at the conventional $5 \%$ level and amounted to -0.211 in the period $1960-1978$, and became strongly significant and large (-0.772 to be compared to -0.606 in our restricted sample) in the period 1978-1998. A very similar pattern can be found analyzing the behavior of the coefficient affecting the investment/output ratio. Over 
Table 15: Growth Regressions (WSSA)

\begin{tabular}{lcccccccc}
\hline \hline & \multicolumn{2}{c}{ OLS } & \multicolumn{2}{c}{ WLS } & \multicolumn{2}{c}{ IV } & \multicolumn{2}{c}{ IV } \\
& $60-78$ & $78-98$ & $60-78$ & $78-98$ & $60-78$ & $78-98$ & $60-78$ & $78-98$ \\
\hline Const. & 0.143 & 0.175 & 0.136 & 0.187 & 0.126 & 0.165 & 0.182 & 0.170 \\
& $(0.024)$ & $(0.024)$ & $(0.021)$ & $(0.020)$ & $(0.025)$ & $(0.026)$ & $(0.026)$ & $(0.035)$ \\
$y_{0}$ & -0.010 & -0.011 & -0.009 & -0.013 & -0.008 & -0.011 & -0.014 & -0.011 \\
& $(0.002)$ & $(0.002)$ & $(0.002)$ & $(0.002)$ & $(0.002)$ & $(0.002)$ & $(0.002)$ & $(0.003)$ \\
$n$ & -0.211 & -0.772 & -0.174 & -0.737 & -0.266 & -0.798 & -0.127 & -0.743 \\
& $(0.180)$ & $(0.148)$ & $(0.173)$ & $(0.146)$ & $(0.183)$ & $(0.151)$ & $(0.157)$ & $(0.170)$ \\
$i / y$ & 0.011 & 0.021 & 0.013 & 0.018 & 0.007 & 0.018 & 0.005 & 0.016 \\
& $(0.003)$ & $(0.003)$ & $(0.003)$ & $(0.003)$ & $(0.003)$ & $(0.004)$ & $(0.003)$ & $(0.005)$ \\
Educ. & - & - & - & - & - & - & 0.014 & 0.003 \\
& & & & & & & $(0.004)$ & $(0.007)$ \\
SSA-Dum. & -0.018 & -0.012 & -0.017 & -0.019 & -0.019 & -0.013 & -0.020 & -0.016 \\
& $(0.004)$ & $(0.004)$ & $(0.004)$ & $(0.004)$ & $(0.004)$ & $(0.005)$ & $(0.005)$ & $(0.006)$ \\
$R^{2}$ & 0.32 & 0.52 & 0.44 & 0.60 & - & - & - & - \\
\hline $\mathcal{Q}$ (Total) & 6.335 & {$[0.042]$} & 8.616 & {$[0.013]$} & 5.619 & {$[0.060]$} & 8.944 & {$[0.011]$} \\
$\mathcal{Q}\left(y_{0}\right)$ & 0.371 & {$[0.543]$} & 3.158 & {$[0.076]$} & 0.627 & {$[0.429]$} & 0.451 & {$[0.502]$} \\
$\mathcal{Q}(n, i / y)$ & 14.466 & {$[0.001]$} & 9.147 & {$[0.010]$} & 12.255 & {$[0.002]$} & 13.464 & {$[0.001]$} \\
$\mathcal{Q}$ (Educ.) & - & - & - & - & - & - & 1.921 & {$[0.166]$} \\
\hline \hline
\end{tabular}

Note: Standard errors into parenthesis, p-values into brackets. WLS: Weights are given by the log of the population. IV: the instruments are the initial level of $(\mathrm{i} / \mathrm{y})$, the average $(\mathrm{c} / \mathrm{y})$ over the subsample, and the average growth rate of population over the 15 first periods of the sub-sample. 106 observations except for the last column where only 86 observations are available.) 
the first sub-period, this coefficient was significant and amounted to 0.011. Over the second sub-period, it remained significant and rose to 0.021 - therefore doubling between the two sub-periods. The stability test accordingly indicates a significant structural break between the two periods $(\mathrm{p}-$-value $=0)$. The results are once again robust to the adoption of a WLS procedure and instrumental variable estimation.

Beyond our benchmark regression, table 15 also reports an IV estimates augmented to include an education variable. The education variable we include is a weighted average of school enrollment for primary, secondary and tertiary degrees of education. ${ }^{32}$ Data availability problems imply that 20 countries are lost in that experiment. Interestingly, the results indicate that over the 1960-1978 sub-period education contributed significantly and positively to growth, but over the 1978-1998 sub-period this effect vanished, which once again suggests that the importance of education did not increase over time. Furthermore, the inclusion of education in the growth equation has basically two effects: (i) it makes convergence parameter very stable over the two sub-periods and (ii) it reinforces the increasing effect of accumulation factors. For instance, on average the effects of population growth are multiplied by a factor of 5 and the effects of investment are multiplied by almost 3 . This is actually slightly stronger than the effects we obtained previously.

Hence, it appears that the introduction of Sub Saharan African countries does not affect our observation that the importance of traditional growth factors increased substantially from the period 1960-1978 to the period 1978-1998.

\subsection{Implementing the decomposition}

We now undertake a decomposition of the observed changes in the world distribution of outputper worker for our wider sample of countries. We want to argue that once we take care of a specific effect characterizing sub Saharan African countries in the early period (1960-78), then the explanation we presented in section $4-$ i.e. the increase importance of tradition factors of accumulation over the later period - remains capable of explaining the bulk of changes observed between 1978 and 1998.

Figure 8 reports the decomposition of changes in the distribution controlling for different effects. In performing this decomposition, we use our estimates from the OLS regression in table 15 . The first observation we want to highlight concerns the change in the distribution from 1960 to 1978. To this end, in panel (a) of figure 8 we report the observed distribution of output per worker in 1960 (grey line) and in 1978 (dark plain line), and the distribution of counterfactual 1978 output per worker (dark dashed line) where we control for all effects specific to sub Saharan African countries. More specifically, we built a counterfactual output per worker series for 1978 taking into account (i) the sub Saharan dummy and (ii) the sub Saharan unobservable component.

\footnotetext{
${ }^{32}$ See footnote 26 for details on this variate.
} 
Figure 8: Decomposing the Observed Changes in the Distributions

(a) Sub-Saharan effect (60-78)

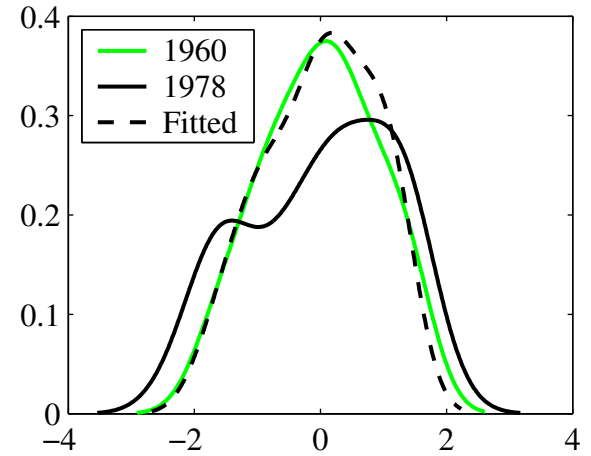

(c) Distributions $(\mathrm{n}, \mathrm{i} / \mathrm{y})$



(e) Observables $(\mathrm{n}, \mathrm{i} / \mathrm{y})$

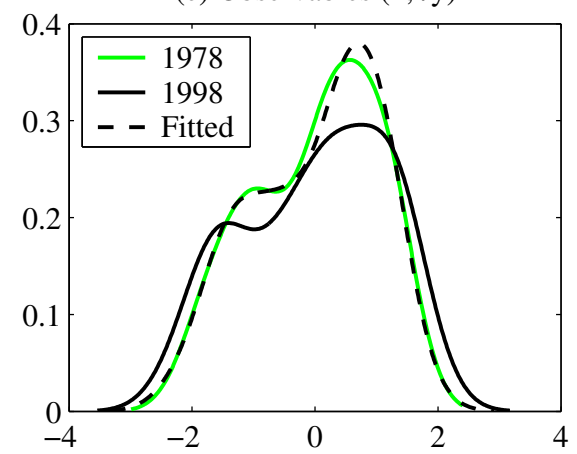

(b) Sub-Saharan effect (78-98)

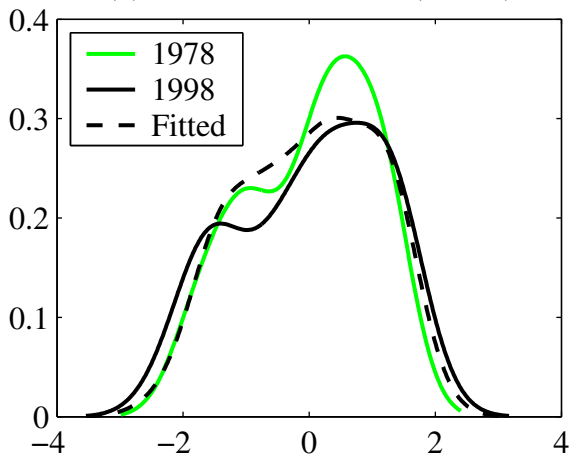

(d) Coefficients (n,i/y)

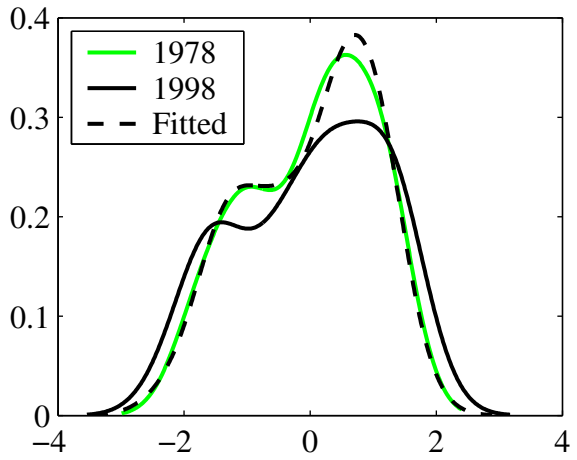

(f) Obs. (n,i/y) + Sub-Saharan effect (60-78)

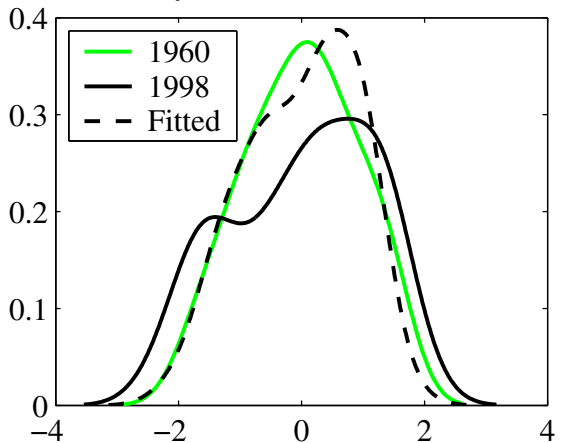


That is, we build the counterfactual as follows:

$$
\widehat{y}_{i}^{78}=y_{i}^{78}-18 \times\left(\beta_{D}^{60-78} D_{i}^{S S A}+D_{i}^{S S A} \times \varepsilon_{i}^{60-78}\right)
$$

where $D_{i}^{S S A}=1$ for sub-saharan African countries and 0 otherwise, $\beta_{D}^{60-78}$ is the associated coefficient. In this counterfactual, the sub-Saharan African countries effectively only contribute their fitted mean values based on the convergence, population growth and investment variables and parameters. As can be seen from the figure, once we control for all effects specific sub Saharan African countries, the hump-shape observed in 1978 disappears: the counterfactual 1978 distribution is almost the same as the 1960 distribution. We perform the same exercise for the period 1978 to 1998 to see if this effect is repeated in the second period. The results from this exercise is reported in panel (b) of figure 8. In this case, the effects specific to sub Saharan effect are not sufficient to reproduce the 1978 distribution. Indeed, there remains substantial movement in the distribution which needs to be explained. Therefore, we now turn to examining whether changes in the growth process can explain the movements observed between 1978 and 1998.

In panel (c) of figure 8, we examine the effects induced by changes in the distribution of traditional accumulation factors, that is, population growth and investment rate. This counterfactual experiment is based on equation (5). As in our restricted sample, changes in the distribution of accumulation forces accounts for little of the observed change in output per worker distribution. Conversely, as can be seen from panel (d) of figure 8, and just as in our restricted sample, the modification in the shape of the distribution seems to originate from a change in the coefficients of accumulation forces. In fact, again as in our restricted sample, this change in the coefficients tends to over-explain the observed changes in the distribution - though to a lesser extent than we observed with the restricted sample. If, as in panel (e) of the figure, we combine the effects of changes in the distribution of accumulation factors and changes in their related coefficients the counterfactual experiment being then based on equation (8) - the 1998 distribution (dark plain line) is brought close to the 1978 distribution (grey line). In other words, the observed changes in the shape of the world output per worker distribution between 1978 and 1998 - just as in our restricted sample - appears to be the reflection of a change affecting the accumulation process that drives output growth.

As a final exercise, we correct both for the change in the observable component of accumulation and for the specific sub Saharan Africa effect observed in the period 1960-78. In this case - as illustrated by panel (f) of the figure - this counterfactual brings the 1998 distribution almost inline with the 1960 distribution, implying that two factors are important for explaining the world distribution of output per worker over the period 1960-98: (i) a dramatic change in the importance of traditional factors affecting growth after 1978 and (ii) the bad residual draws experienced by sub Saharan African countries during the earlier period of the sample. 


\section{Discussion}

The results we have presented up to this point invite the question of what type of model could explain the observed increase in importance of traditional growth factors. Although a complete answer to this question is beyond the scope of the current paper, we nevertheless want to highlight three elements that are potentially relevant for answering such a question. First, following Bernanke and Gürkaynak [2001], we want to examine whether the mechanisms at play most likely reflects traditional neo-classical forces or if, alternatively, some element of endogenous technological change is likely part of the story. Second, we want to examine whether international trade is potential a relevant element to be considered.

\subsection{Could it all be due to Neoclassical forces?}

In recent work, Bernanke and Gürkaynak [2001] have examined whether total factor productivity (TFP) growth across countries appears mainly exogenous with respect to a country's accumulation path, or if, conversely, a country's accumulation affects TFP growth and thereby suggests some form of externality or endogenous technological change. In this section, we pursue this idea one step further by comparing the behaviour of TFP over the periods 1960-78 and 1978-98. Our goal is to assess whether the behaviour of TFP has changed over this period, as has been the case for GDP growth, or whether the observed increase in importance of traditional growth factors is restricted to the output growth process. To perform this exercise, we build TFP series for each country by subtracting from the rate of growth of output per worker the share weighted contribution of the rate of growth of physical capital per worker. Since we do not have good share data for all these countries, we build two TFP series using a share of capital of 0.35 - which is close to the average share of capital across-countries reported in Bernanke and Gürkaynak [2001] ( we verified that our results are robust to using a share of capital of 0.5 instead of 0.35). Capital series were constructed using the perpetual inventory method, with the details of this construction given in appendix A.

Table 16 reports estimation results for TFP regressions. In the first four columns of the table, we report estimation results for OLS and IV regressions relating the growth in TFP to the traditional accumulation factors (population growth and investment rate), and an additional term that aims at capturing a potential technological catchup phenomenon - i.e. the initial (log) level of TFP for the given sub-period. Note that the results presented in this table correspond to NSSA sample of countries. ${ }^{33}$ The set of instrument we use is that corresponding to $\mathrm{IV}^{\star}$. The main feature that emerges from this table is that the results found for output growth appear to apply for TFP growth. In particular, the magnitude of the coefficients affecting the two traditional accumulation forces increased significantly between the two sub-periods. The stability tests, both for our OLS and IV estimations, clearly lead to a strong rejection of the stability of these

\footnotetext{
${ }^{33}$ Results are robust to including sub-Saharan African countries in the sample.
} 
Table 16: TFP regressions

\begin{tabular}{lcccccccc}
\hline \hline & \multicolumn{2}{c}{ OLS } & \multicolumn{2}{c}{ IV1 } & \multicolumn{2}{c}{ IV1 } & \multicolumn{2}{c}{ IV2 } \\
\cline { 2 - 10 } & $60-78$ & $78-98$ & $60-78$ & $78-98$ & $60-78$ & $78-98$ & $60-78$ & $78-98$ \\
\hline Const. & 0.118 & 0.112 & 0.111 & 0.114 & 0.030 & 0.038 & 0.142 & 0.125 \\
& $(0.016)$ & $(0.021)$ & $(0.017)$ & $(0.022)$ & $(0.005)$ & $(0.006)$ & $(0.023)$ & $(0.034)$ \\
$n$ & -0.073 & -0.481 & -0.122 & -0.484 & -0.201 & -0.451 & -0.010 & -0.548 \\
& $(0.125)$ & $(0.130)$ & $(0.128)$ & $(0.133)$ & $(0.151)$ & $(0.144)$ & $(0.130)$ & $(0.138)$ \\
$i / y$ & 0.009 & 0.014 & 0.005 & 0.015 & 0.003 & 0.013 & 0.001 & 0.017 \\
& $(0.002)$ & $(0.003)$ & $(0.002)$ & $(0.003)$ & $(0.003)$ & $(0.003)$ & $(0.004)$ & $(0.005)$ \\
$T F P_{0}$ & -0.014 & -0.012 & -0.014 & -0.012 & - & - & -0.019 & -0.013 \\
& $(0.003)$ & $(0.003)$ & $(0.003)$ & $(0.003)$ & & & $(0.004)$ & $(0.006)$ \\
Educ. & - & - & - & - & - & - & 0.013 & -0.000 \\
& & & & & & & $(0.006)$ & $(0.011)$ \\
$R^{2}$ & 0.38 & 0.43 & - & - & - & - & - & - \\
\hline $\mathcal{Q}$ (Total) & 9.734 & {$[0.021]$} & 12.830 & {$[0.005]$} & 8.050 & {$[0.018]$} & 22.467 & {$[0.000]$} \\
$\mathcal{Q}$ (TF $\left.P_{0}\right)$ & 0.276 & {$[0.599]$} & 0.157 & {$[0.692]$} & - & - & 0.899 & {$[0.343]$} \\
$\mathcal{Q}(n, i / y)$ & 9.071 & {$[0.011]$} & 12.160 & {$[0.002]$} & - & - & 14.198 & {$[0.001]$} \\
$\mathcal{Q}$ (Educ) & - & - & - & - & - & - & 1.028 & {$[0.311]$} \\
\hline \hline
\end{tabular}

Note: Standard errors into parenthesis, p-values into brackets. IV1: the instruments are the initial level of $(\mathrm{i} / \mathrm{y})$, the average (c/y) over the sub-sample, and the average growth rate of population over the 15 first periods of the sub-sample. (75 observations) IV2: the set of instruments of IV1 is completed by the years of schooling to instrument the education variable. (68 observations)

coefficients. In particular, if we consider the coefficient measuring the impact of investment on TFP growth, we find that it was multiplied by a factor of 3 between the two sub-periods when estimated with IV. Similarly the magnitude of the population growth effect was multiplied by a factor of 4. Furthermore, those two coefficients are strongly significant over the second subperiod, indicating that treating TFP as exogenous over this period would be unreasonable. If we now focus on the coefficient on the initial level of TFP, we find that - whatever the estimation method - it is strongly significant but remains stable over the two sub-periods. Hence, these data also suggest that there was significant technological catchup taking place over the entire period between 1960 and 1998. Even if we decide to abstract from this catchup phenomenon (third set of results in table 16), accumulation forces are still found to be unstable between the two sub-periods, but the change in population growth is less pronounced.

To complete the picture regarding TFP growth, in the last two columns of the table we introduce educational investment ${ }^{34}$ in the regression, and we add the years of schooling in the list of instruments. The results are once again very close to those found for the output growth process. In particular, there is no indication that educational investment has played more of a role in the second period. Furthermore, the inclusion of educational investment does not reduce the significance of our previous observations.

\footnotetext{
${ }^{34}$ This variable corresponds to the weighted sum of primary, secondary and tertiary enrolments rates.
} 
To sum up, the results of table 16 suggests that explanations of the observed changes in the world distribution of income between 1960 and 1998 should include an endogenous growth type mechanism that explains the observed increase in importance of traditional growth factors on TFP growth.

\subsection{Is trade relevant?}

We now want to explore whether international trade may also be a relevant component for explaining the observed increase in the role of traditional growth factors. To this end, in table 17, we report a set of regressions where we split the sample into two groups depending on their ratio of total exports plus imports over GDP, which is a measure of openness available in the Penn World Tables. More precisely, we split the sample according to the median value of the average of this openness variable over the period 1960-78. ${ }^{35}$ We report results based on our parsimonious specification where $\mathcal{K}$ is used to capture the effects of traditional growth forces. The set of instruments used is again $\mathrm{IV}^{\star}$. The results reported in the first two columns closely parallels those in table 5 . The main feature we want to highlight from this table is the difference

Table 17: Growth Regressions and Openness

\begin{tabular}{lcccccc}
\hline \hline & \multicolumn{2}{c}{ Total } & $\bar{O}_{60-78}<\operatorname{med}\left(\bar{O}_{60-78}\right)$ & $\bar{O}_{60-78} \geqslant \operatorname{med}\left(\bar{O}_{60-78}\right)$ \\
\cline { 2 - 7 } & $60-78$ & $78-98$ & $60-78$ & $78-98$ & $60-78$ & $78-98$ \\
\hline Const. & 0.121 & 0.121 & 0.096 & 0.125 & 0.169 & 0.126 \\
\multirow{2}{*}{$y_{0}$} & $(0.021)$ & $(0.022)$ & $(0.023)$ & $(0.024)$ & $(0.035)$ & $(0.041)$ \\
& -0.011 & -0.014 & -0.009 & -0.013 & -0.015 & -0.015 \\
$\mathcal{K}$ & $(0.002)$ & $(0.002)$ & $(0.003)$ & $(0.003)$ & $(0.004)$ & $(0.004)$ \\
& 0.009 & 0.029 & 0.017 & 0.018 & 0.006 & 0.041 \\
\hline Stab.(Total) & 17.846 & {$[0.000]$} & 1.565 & {$[0.457]$} & 48.966 & {$[0.000]$} \\
Stab. $\left(y_{0}\right)$ & 0.834 & {$[0.361]$} & 1.453 & {$[0.228]$} & 0.001 & {$[0.971]$} \\
Stab. $(\mathcal{K})$ & 15.647 & {$[0.000]$} & 0.048 & {$[0.827]$} & 27.795 & {$[0.000]$} \\
\hline \hline
\end{tabular}

Note: Standard errors into parenthesis, p-values into brackets. the instruments are the initial level of $(\mathrm{i} / \mathrm{y})$, the average $(\mathrm{c} / \mathrm{y})$ over the sub-sample, and the average growth rate of population over the 15 first periods of the sub-sample. $O$ denotes the degree of openess of the economies as measured by the ratio of total exports plus imports to gdp.

in the behaviour of estimates between the more open countries $\left(\bar{O}_{60-78} \geqslant \operatorname{med}\left(\bar{O}_{60-78}\right)\right)$ and the less open countries $\left(\bar{O}_{60-78}<\operatorname{med}\left(\bar{O}_{60-78}\right)\right)$. In particular, for the more closed economies, we do not observed a significant change in importance of traditional growth factors; while for the more open economies we see a very significant and substantial change in the importance of this factor. Moreover, the difference in behaviour is quantitatively quite large. In the case of the

\footnotetext{
${ }^{35}$ We experimented different assumption on the splitting of countries, making it depend on either the degree of openness in 1960, or the average degree of openness in the second sub-period, and found no significant differences with respect to the results we are currently reporting.
} 
more closed economies, the increase in the coefficient on $\mathcal{K}$ was only 0.001 , while it is 0.035 (35 times bigger) for the sample of more open economies. It is immediately worth noting that this pattern contrasts sharply with previous splits, whereby the instability result was found to be robust to dividing the sample along either income or schooling lines. Hence the results in table 17 suggest that the observed rise in importance of traditional growth factors, and the associated twin-peaks phenomenon, may reflect the process of globalization or, alternatively, may reflect changes in the prices of traded goods. ${ }^{36}$

\section{Concluding remarks}

The object of the paper has been to shed light on the relative importance of different factors reshaping the world distribution of output-per-worker between 1960 and 1998. To this end, we have broken down the problem in several steps. Firstly, we discuss why it may be useful to examine sub-Saharan Afican countries apart from the rest of the sample. Secondly, we showed why it is relevant to separate the time period into two sub-periods: 1960-78 and 1978-98. Thirdly, we present a simple decomposition methodology which allows to separate observed changes in the distribution output per worker into three components: (i) changes in the distribution of observable factors affecting growth, (ii) changes in the importance of the observable factors affecting growth, and (iii) changes in the distribution of residual (or un-measured) factors affecting growth. Our main finding is that most of the change in distribution observed since 1978 appears driven by changes in the importance of the two traditional factors reflecting the gains to physical capital accumualtion - that is the investment rate and the rate of population growth. In contrast, we found that factors other than that associated with capital deepening were relevant only for understanding the sub-Saharan African countries in the early period.

We take the results of our exercise as indicating new directions for research aimed at understanding global trends and the associated changes in the world distribution of income since 1960. In particular, we think that such research should investigate the reasons for the substantive increase in the social returns to capital accumulation we document in the period 1978-98 relative to $1960-78$. We believe that it is only by explaining these changes that one will explain the observed change in the distribution of output-per-worker. As a preliminary step in this direction, we have argued that an explanation for this change will likely involve (i) some element of endogenous technical change associated with capital deepening externalities, (ii) some element of international transmission through trade.

\footnotetext{
${ }^{36}$ It is interesting to note that, over the 1978-98 period, the estimated speed of convergence in the more opened economies is identical to that in the more closed. If this speed of convergence is interpreted as a reflection of technological diffusion, which would be consistent with our results from the TFP regressions, it suggests that the differences between the more open and more closed economies is not due to differences in technological diffusion.
} 


\section{References}

Barro, R. and J.W. Lee, International Comparisons of Educational Attainment, Journal of Monetary Economics, 1993, 32 (3), 363-394.

Beaudry, P. and F. Collard, Why has the Employment-Productivity Tradeoff among Industrialized Countries been so Strong?, Working Paper 8754, NBER 2002.

Benhabib, J. and M.M. Spiegel, The Role of Human Capital in Economic Development: Evidence from Aggregate Cross-Country Data, Journal of Monetary Economics, 1994, 34 (2), $143-174$.

Bernanke, B.S. and R.S. Gürkaynak, Is Growth Exogenous? Taking Mankiw, Romer and Weil Seriously, in B.S. Bernanke and K. Rogoff, editors, NBER Macroeconomics Annual, Vol. 16, Cambridge MA: MIT Press, 2001, chapter 1.

Durlauf, S.N. and D.T. Quah, The New Empirics of Economic Growth, in J.B. Taylor and Woodford M., editors, Handbook of Macroeconomics, Vol. 1, Amsterdam: Esevier Science, 1999.

Jones, C.I., On the Evolution of the World Income Distribution, Journal of Economic Perspectives, 1997, 11 (3), 19-36.

Juhn, C., K.M. Murphy, and B. Pierce, Wage Inequality and the Rise in Returns to Skill, Journal of Political Economy, 1993, 101 (3), 410-442.

Klenow, P.J. and A. Rodrìguez-Clare, The Neoclassical Revival in Growth Economics: Has it Gone too Far?, in B.S. Bernanke and J. Rotemberg, editors, NBER Macroeconomics Annual, Vol. 12, Cambridge MA: MIT Press, 1997, chapter 2.

Krueger, A.B. and M. Lindhal, Education for Growth: Why and for Whom?, Journal of Economic Literature, 2001, 39 (4), 1101-1136.

Lucas, R., On the Mechanisms of Economic Development, Journal of Monetary Economics, 1988, 22, 3-42.

Mankiw, N.G., D. Romer, and D.N. Weil, A Contribution to the Empirics of Economic Growth, Quarterly Journal of Economics, 1992, 107 (2), 407-437.

Quah, D., Empirical Cross-Section Dynamics in Economic Growth, European Economic Review, 1993, $37(2 / 3), 426-434$.

— Empirics for Growth and Distribution: Polarization, Stratification, and Convergence Clubs, Journal of Economic Growth, 1997, 2 (1), 27-59.

Sala-i-Martin, X., The World Distribution of Income (estimated from Individual Country Distributions), miméo, Columbia University 2002. 
Solow, R.M., A Contribution to the Theory of Economic Growth, Quarterly Journal of Economics, 1956, 70 (1), 65-94.

Uzawa, H., Optimum Tehcnical Change in an Aggregative Model of Economic Growth, International Economic Review, 1965, 6 (1), 18-31. 


\section{A Data}

Two datasets were used in this study. Most of the data are taken from the latest version of the Penn World Table 6.0 downloadable from http://webhost.bridgew.edu/baten/.

Education data are taken from the Barro and Lee [1993] dataset, which is downloadable from http://www.nuff.ox.ac.uk/Economics/Growth/datasets.htm.

\section{A.1 Main data}

Our measure of income, $y$, is the logarithm of real GDP chain per worker (RGDPW in PWT 6.0), where the definition of a worker is based of economically active population.

Population is POP in PWT 6.0. Workers are computed as the population from 15 to 64 obtained from

$$
\mathrm{POPW}_{t}=\frac{\text { real GDP chain per capita }}{\text { real GDP chain per worker }} \times \text { population }=\frac{\mathrm{RGDPL}}{\mathrm{RGDPW}} \times \mathrm{POP}
$$

$n$ then denotes the rate of growth of the 15-64 population.

The corresponding annualized average rate of growth for the variable $Z$ within the sub-sample $[\mathrm{t} ; \mathrm{t}+\mathrm{n}]$ is computed as

$$
\Delta z=\frac{\log \left(Z_{t+n}\right)-\log \left(Z_{t}\right)}{n}
$$

The share of consumption at constant prices corresponds to the variable KC in the PWT 6.0. In the IV procedure, the average share of consumption $c / y$ over the sub-sample $[\mathrm{t} ; \mathrm{t}+\mathrm{n}]$ is computed as

$$
\frac{1}{n} \sum_{j=1}^{n} \log \left(\mathrm{KC}_{t+j} / 100\right)
$$

The investment ratio at constant prices corresponds to the variable KI in the PWT 6.0 and is divided by 100 . In the regressions, $i / y$ then refers to the logarithm of this variable. It is also used to compute our accumulation variable that accounts for the overall accumulation effect, which is given by

$$
\mathcal{K} \equiv \log \left(\frac{\mathrm{KI}}{(1+\gamma)(1+n)+\delta-1}\right)
$$

We followed Mankiw et al. [1992] and assume a annual depreciation rate of $\delta=0.03$ and a rate of growth of technical progress, $\gamma$, of $2 \%{ }^{37}$

Furthermore, the investment share is used to compute the capital stock per worker - needed to compute the TFP — using the permanent inventory scheme

$$
(1+n) k_{t+1}=i_{t}+(1-\delta) k_{t}
$$

\footnotetext{
${ }^{37}$ We performed robustness checks but did not find any significant effect of a change in either $\delta$ or $\gamma$.
} 
where $k=K / L . k_{1960}$ is obtained as

$$
k_{1960}=\frac{\left(\frac{1}{10} \sum_{t=1960}^{1970} \mathrm{KI}_{t}\right) \mathrm{RGDPW}_{1960}}{\left(1+\bar{n}_{60-70}\right)(1+\gamma)+\delta-1}
$$

where

$$
\bar{n}_{60-70} \equiv \frac{\log \left(\mathrm{POPW}_{1970}\right)-\log \left(\mathrm{POPW}_{1960}\right)}{10}
$$

We also followed Mankiw et al. [1992] and assume a annual depreciation rate of $\delta=0.03$ and a rate of growth of technical progress, $g$, of $2 \%$. The measure of TFP then follows

$$
T F P=\log (\mathrm{RGDPW})-\alpha \log (k)
$$

where $\alpha$ is set to 0.35 and 0.5 to check robustness.

\section{A.2 Education data}

The education variables are borrowed from Barro and Lee [1993]. We consider essentially 3 measures of human capital. The first one is related to the overall enrollment rate in education. Assuming that, on average, most people sped 6 years in primary schooling, 6 years in secondary schooling and 4 years in higher schooling, we first define the index

$$
\log \left(\frac{6 \times \mathrm{P}+6 \times \mathrm{S}+4 \times \mathrm{H}}{16}\right)
$$

where P, S and H respectively denote the total gross enrollment ratio for, respectively, primary, secondary and higher schooling.

Our second measure of the education variable also relates to the enrollment rate but focuses on the primary and secondary schooling. It is built as

$$
\log \left(\frac{\text { DURP } \times \text { P }+ \text { DURS } \times \text { S }}{\text { DURP }+ \text { DURS }}\right)
$$

where DURP and DURS respectively denote the duration in years of, respectively, the primary and secondary education in 1965.

Our last education variable, Years, should be more understood as a stock since it is given by

$$
\log (\text { HUMAN })
$$

where HUMAN is the average schooling years in the total population over 25 .

Note that these measures are only reported every 5 years in the database from 1960 to 1985 . We actually used an average of years 1960 and 1965 for the first sub-sample and 1975 and 1980 for the second sub-sample. We restrict ourselves to 2 periods for the average for data availability purposes. 


\section{A.3 Composition of the sample}

Our restricted sample of 75 countries consists of:

Argentina, Australia, Austria, Belgium, Bangladesh, Bolivia, Brazil, Barbados, Botswana, Canada, Switzerland, Chile, China, Colombia, Costa Rica, Cyprus, Denmark, Dominican Republic, Ecuador, Egypt, Spain, Finland, Fiji, France, United Kingdom, Greece, Guatemala, Guyana, Hong Kong, Honduras, Indonesia, India, Ireland, Iran, Iceland, Israel, Italy, Jamaica, Jordan, Japan, Republic of Korea, Sri Lanka, Lesotho, Luxembourg, Morocco, Mexico, Mozambique, Malaysia, Namibia, Nicaragua, Netherlands, Norway, Nepal, New Zealand, Pakistan, Panama, Peru, Philippines, Papua New Guinea, Portugal, Paraguay, Romania, Singapore, El Salvador, Sweden, Syria, Thailand, Trinidad and Tobago, Tunisia, Turkey, Taiwan, Uruguay, USA, Venezuela, South Africa,

When we move to our enlarge sample of 106 countries we add the following 31 sub-saharan African countries:

Burundi, Benin, Burkina Faso, Central African Republic, Ivory Coast, Cameroon, Republic of Congo, Comoros, Cape Verde, Ethiopia, Gabon, Ghana, Guinea, The Gambia, Guinea-Bissau, Kenya, Madagascar, Mali, Mauritania, Mauritius, Malawi, Niger, Nigeria, Rwanda, Senegal, Seychelles, Chad, Togo, Tanzania, Uganda, Zambia.

\section{B Kernel density estimates}

The density estimates are computed using a kernel density estimator. Given a set of data $\mathcal{Y}=\left\{y_{i}\right\}_{i=1}^{N}$, the Rosenblatt-Parzen kernel density estimator of $\mathcal{Y}$ is given by

$$
\widehat{f}(y)=\frac{1}{N h} \sum_{i=1}^{N} K\left(\frac{y-y_{i}}{h}\right)
$$

where the kernel, $K($.$) , is a continuous, bounded, symmetric real-valued function that integrates$ to 1. For our purpose, we used a Gaussian kernel, $K(\omega)=\exp \left(-\omega^{2} / 2\right) / \sqrt{2 \pi}$, with a bandwidth parameter, $h$, chosen as $h=1.0592 \sigma N^{-1 / 5}$ where $\sigma$ is the standard deviation of the data and $N$ is the number of observations. 
Figure 9: Decomposing the observed changes in the distributions (IV)

(a) Observables $\left(y_{0}\right)$

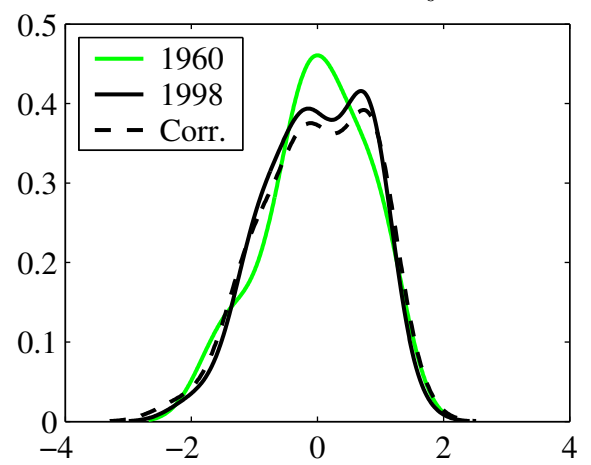

(c) Distribution $(\mathrm{n}, \mathrm{i} / \mathrm{y})$



(e) Observables (n,i/y)

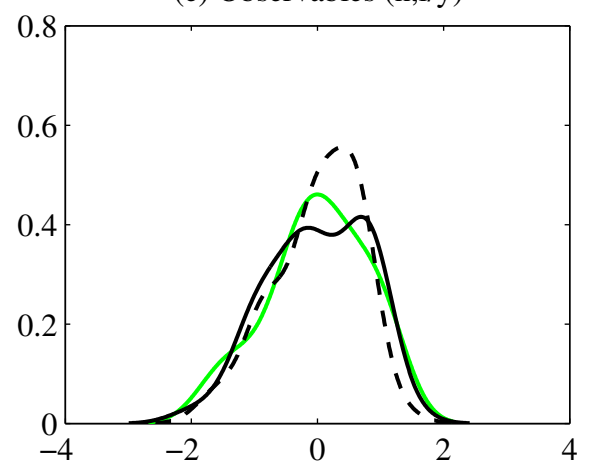

(b) Coefficients $\left(\beta_{\mathrm{y}}^{78-98}=0\right)$

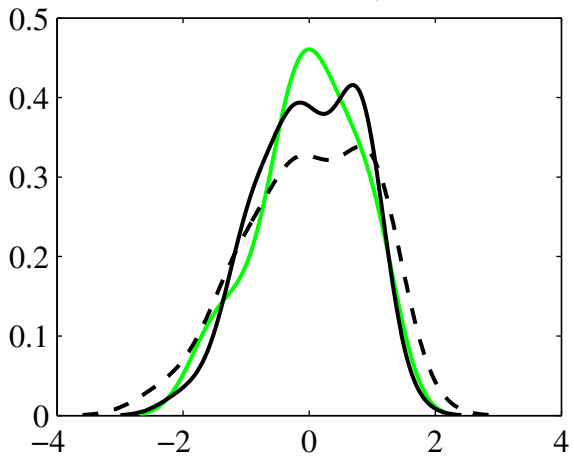

(d) Coefficients $(\mathrm{n}, \mathrm{i} / \mathrm{y})$

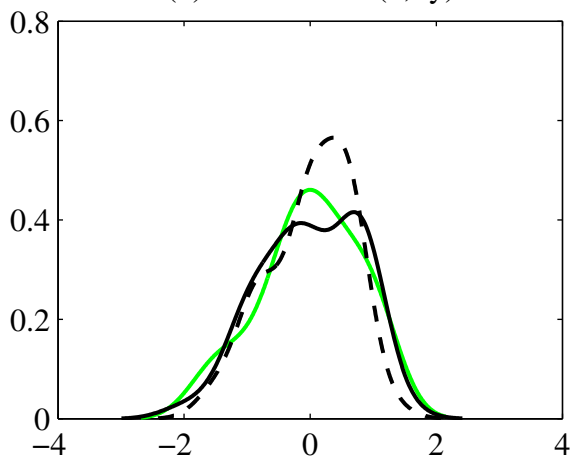

(f) Unobservables

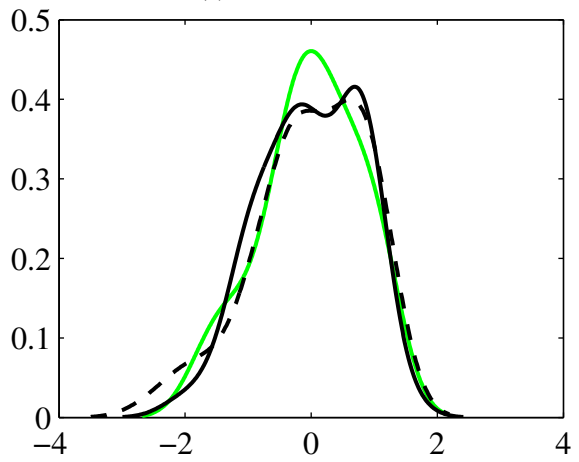

Note: The decomposition is based on the IV3 regression presented in table 4 . 